\title{
La régulation de la « beauté » dans la doctrine hermogénienne et la tradition proto-byzantine
}

\section{Régis Caruso}

\section{(2) OpenEdition}

1 Journals

Édition électronique

URL : http://journals.openedition.org/rhetorique/1017

DOI : $10.4000 /$ rhetorique. 1017

ISSN : 2270-6909

Éditeur

UGA Éditions/Université Grenoble Alpes

Édition imprimée

ISBN : 978-2-37747-248-2

\section{Référence électronique}

Régis Caruso, «La régulation de la «beauté » dans la doctrine hermogénienne et la tradition protobyzantine », Exercices de rhétorique [En ligne], 15 | 2020, mis en ligne le 11 novembre 2020, consulté le 03 décembre 2020. URL : http://journals.openedition.org/rhetorique/1017 ; DOI : https://doi.org/ 10.4000/rhetorique. 1017

\section{Ce document a été généré automatiquement le 3 décembre 2020.}

\section{(c) (i) (8)}

Les contenus de la revue Exercices de rhétorique sont mis à disposition selon les termes de la Licence Creative Commons Attribution - Pas d'Utilisation Commerciale - Partage dans les Mêmes Conditions 4.0 International. 


\title{
La régulation de la « beauté » dans la doctrine hermogénienne et la tradition proto-byzantine
}

\author{
Régis Caruso
}

1 Les figures de la tradition dite gorgianique ${ }^{1}$, dont relèvent certaines figures de la beauté ( $\kappa a ́ \lambda \lambda o \varsigma)$ dans le traité du rhéteur Hermogène intitulé Les Catégories stylistiques du

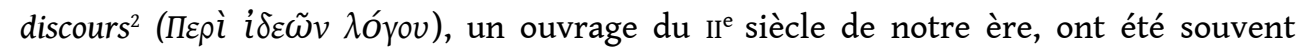
décriées par les Anciens, qui en ont prescrit un usage limité. Leur emploi, exposant à un « vice » rhétorique, a éveillé la méfiance des professionnels de l'éloquence et a été mis au compte d'une esthétique oratoire périmée et de mauvais goût par certains critiques, notamment Denys d'Halicarnasse ${ }^{3}$. Malgré leur piètre réputation, ces figures n'ont pourtant jamais disparu des doctrines stylistiques grecques, non plus que de la littérature antique, grecque ou latine, puis byzantine et européenne... Ce qui distingue tel rhéteur de tel autre n'est pas la présence ou l'absence chez lui des figures dites gorgianiques mais plutôt leur nombre, leurs noms, et surtout leur degré d'intégration au sein d'un ensemble esthétique dûment théorisé, car leur relation au Beau, conformément à l'étymologie du terme « esthétique " ( $\alpha$ l̆ $\sigma \theta \eta \sigma \iota$, sensation, sentiment), est ce qui caractérise ces figures. Il faut garder présent à l'esprit que le Beau dont il est question ici concerne surtout la matérialité sensible de l'énoncé, ce que Jakobson nommait sa "figure phonique", car les rhéteurs et critiques grecs assimilaient généralement la beauté susceptible d'être produite par le langage à une musique capable de séduire un auditoire indépendamment du sens des mots, tel Denys d'Halicarnasse lorsqu'il compare la prose démosthénienne au chant des sirènes.

2 Notre étude a pour but de présenter la conception des figures dites gorgianiques dans

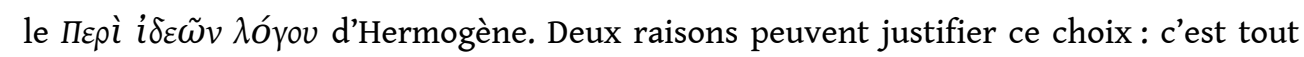
d'abord dans son traité assurément que ces figures sont le plus intimement intégrées à un système unitaire, et que la théorie elle-même, dotée de principes régulateurs, est apte à prévenir tout excès de beauté, par son architecture d'ensemble et par les moyens qu'elle prescrit dans le détail. La théorie hermogénienne peut, à cet égard, être 
considérée comme une réponse nuancée, sûre et définitive aux critiques récurrentes énoncées par les Anciens. Hermogène a, de plus, profondément marqué de son empreinte l'enseignement de la rhétorique à Byzance pendant des siècles: sa conception de la beauté du discours peut donc fournir plus que d'autres quelques clés à qui veut mieux comprendre les critères esthétiques byzantins concernant le discours et les pratiques pédagogiques mises en œuvre pour les appliquer. Nous nous intéresserons ainsi à une scolie rédigée par un commentateur, très probablement entre les $\mathrm{VI}^{\mathrm{e}}$ et $\mathrm{IX}^{\mathrm{e}}$

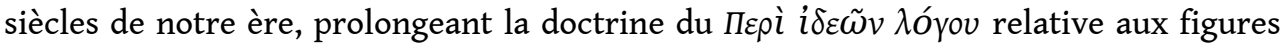
de la beauté. Ce commentateur, qui a voulu compléter l'analyse hermogénienne, l'a assimilée au schéma bien connu de la quadripartita ratio: addition, soustraction, déplacement et substitution. Son exégèse témoigne de l'étroite connivence entre pratique et théorie rhétoriques ainsi que de leur influence réciproque.

3 Pour mieux comprendre Hermogène, il est indispensable d'évoquer les enjeux du débat antique sur l'ornement rhétorique : c'est donc par là que nous commencerons notre étude.

\section{Le débat sur l'ornement rhétorique dans l'Antiquité}

L'analyse hermogénienne des figures dites gorgianiques, pour circonscrite qu'elle soit, nécessite le bref rappel de quelques enjeux du débat antique sur l'ornement, un terme sans équivalent unique en grec et recouvrant, selon les théories et le contexte, des aspects cognitifs, esthétiques et même éthiques. Le point commun qui peut cependant

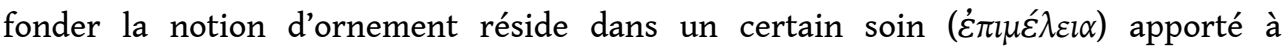
l'expression. Ce débat sur l'ornement confronte les époques et les disciplines: philosophie, rhétorique et critique littéraire, chacune abordant la question de l'ornement rhétorique dans une perspective qui lui est propre. Comme nous le constaterons, le besoin d'élégance dans l'expression est apparu très tôt, mais progressivement l'usage des figures ornementales a fait l'objet de critiques parfois virulentes.

\section{Philosophie et gorgianismes : la forme pour le sens}

Loin de se réduire à une condamnation générale qui serait surtout le fait de Platon ${ }^{4}$, le point de vue des philosophes sur la rhétorique et les ornements oratoires est nuancé. Aristote, ne l'oublions pas, est l'auteur d'une Rhétorique monumentale dont le plan a structuré profondément le champ de cette discipline, et dont le troisième livre est entièrement consacré à la $\lambda \hat{\varepsilon} \xi ı \zeta$, l'expression ou le style. Les recherches d'Aristote ont, de plus, été poursuivies et élargies par son successeur, Théophraste, et de nombreux autres philosophes péripatéticiens à leur suite.

6 Dans la mesure où les considérations d'Aristote sur le style s'appuient sur un matériau rhétorique préexistant, il sera utile d'évoquer avant celle du philosophe une $\tau \dot{\varepsilon} \chi v \eta$ (manuel de technique oratoire) proche de la sienne par quelques aspects, et qui lui fut pour cette raison, bien qu'à tort, attribuée : la Rhétorique à Alexandre. L'ouvrage, dont la datation n'est pas certaine, est peut-être antérieur au traité d'Aristote, mais il expose, en tout cas, des théories qui ont précédé les travaux du Stagirite et peut, à ce titre, mettre en valeur l'apport de la philosophie aux doctrines stylistiques. 
7 La question du soin apporté à l'expression est apparue très tôt dans les traités grecs sur l'art oratoire, sinon dans les premiers traités judiciaires perdus, pour autant qu'on puisse en juger. La Rhétorique à Alexandre affirme sans distinction de genre le besoin d'une expression élégante ${ }^{5}(\tau \dot{\alpha} \dot{\alpha} \sigma \tau \varepsilon \tilde{\imath} \alpha)$ et indique plusieurs moyens de l'obtenir. Le mot $\dot{\alpha} \sigma \tau \varepsilon \tilde{\alpha} \alpha$ en lui-même signifie « de la ville » et oppose la cité à la ruralité, le raffinement à la grossièreté, le débat à l'isolement. Il recouvre notamment les procédés principaux de la tradition dite gorgianique : antithèse, parisose et paromoïose ${ }^{6}$.

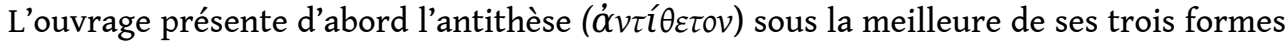

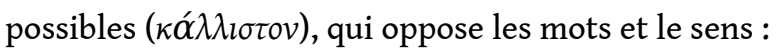

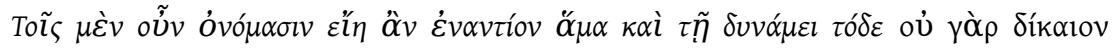

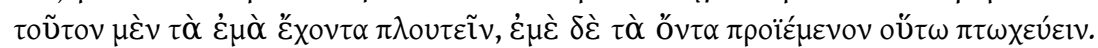
Comme exemple de termes opposés à la fois par les mots et par le sens, on pourrait citer ceci : Car il n'est pas juste que cet individu soit riche en détenant mes biens, tandis que moi, qui ai cédé ce que j'avais, je mendie de la sorte ${ }^{7}$.

Mais l'opposition peut aussi porter sur les mots seulement :

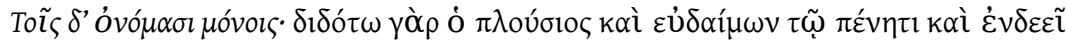

Par les mots seulement : que le riche prospère donne au pauvre indigent ${ }^{8}$.

Et enfin, des faits peuvent également être opposés sans que les mots qui les désignent soient des contraires :

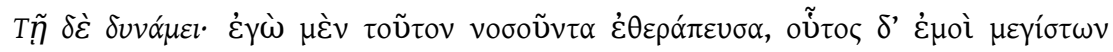

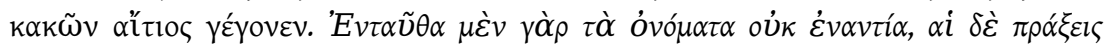
غ̇vavíal.

Par le sens : moi, je l'ai soigné quand il était malade, mais lui, il m'a causé les plus grands torts. Dans cet exemple en effet, les mots ne sont pas opposés, ce sont les actions qui le sont ${ }^{9}$.

Le deuxième procédé, la parisose ( $\pi \alpha \rho i ́ \sigma \omega \sigma \iota)$ ), est ensuite défini par l'auteur comme une égalité susceptible elle aussi de revêtir trois formes.

9 La première, la plus complète, est la seule qui soit illustrée d'un exemple. Elle consiste à rendre égaux le nombre de mots et le nombre de syllabes dans deux membres de phrase qui se suivent. L'exemple donné comporte deux côlons composés chacun de quatre mots et de huit syllabes :

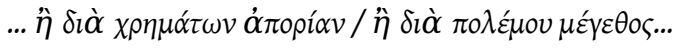

Soit par le manque de richesses, soit par l'importance de la guerre ${ }^{10}$.

Quant aux deux autres parisoses, la première réalise d'un côlon à l'autre l'égalité des mots, la seconde celle des syllabes.

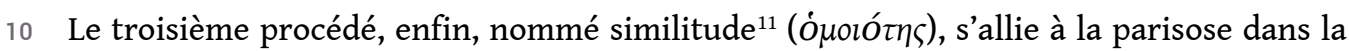
paromoïose ${ }^{12}(\pi \alpha \rho \rho \mu o i ́ \omega \sigma \iota \varsigma)$, et se définit par l'emploi de mots dont les syllabes ou les lettres se ressemblent, surtout en fin de côlon ${ }^{13}$ :

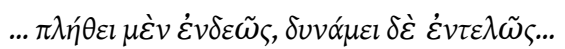

Par le nombre insuffisamment, par la puissance complètement ${ }^{14}$.

Voilà donc, résumée à l'essentiel, la doctrine de la Rhétorique à Alexandre sur les figures dites gorgianiques. On retiendra de l'exposé très fruste de l'auteur qu'il se borne à une description sèche des procédés qu'il recommande. En comparaison, le développement aristotélicien sur la période oratoire se signale par une hauteur de vue nettement supérieure.

11 Aristote s'exprime, en effet, dans le cadre des tâches de l'orateur ${ }^{15}$, avec bien plus de précision sur les qualités du style. Celles-ci sont conçues d'après le modèle des vertus, en tant que ces dernières permettent à une chose ou un animé de remplir leur office. 
Alors qu'il n'était question, dans la Rhétorique à Alexandre, que de moyens susceptibles de rendre le discours élégant ( $\tau \grave{\alpha} \dot{\alpha} \sigma \tau \varepsilon \tilde{l} \alpha$ ), Aristote dénombre plusieurs qualités complémentaires agissant à des niveaux d'analyse différents. Le style doit posséder

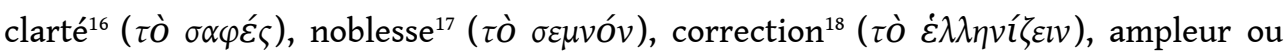

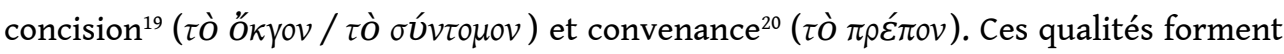

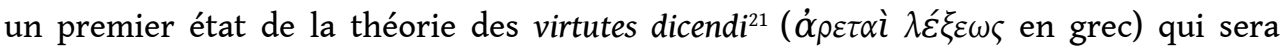
développé ensuite par Théophraste.

12 La question de l'organisation globale de l'expression est envisagée sous la forme d'une

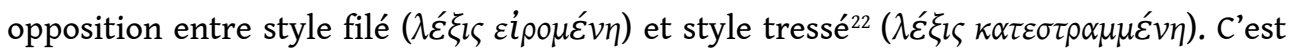
au style tressé, plus moderne, qu'Aristote accorde sa préférence. Le philosophe entend par «style tressé » une expression périodique dans laquelle des membres, les côlons, juxtaposés ou opposés de manière antithétique, sont composés grâce à un rythme non poétique et aux procédés de la parisose et de la paromoïose. On reconnaîtra dans cette description les grands traits d'une prose d'art semblable à celle d'Isocrate. Ce qu'il faut remarquer, c'est qu'Aristote, comme l'auteur de la Rhétorique à Alexandre, ne porte encore aucun jugement négatif sur l'emploi des figures dites gorgianiques en tant que telles. Tout au plus se contente-t-il de mettre en garde l'orateur contre un rythme strictement poétique. La conscience, en effet, que la parisose et la paromoïose participent de la poésie est sans aucun doute présente chez Aristote tout comme elle

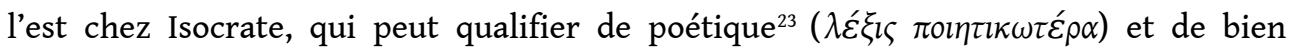
rythmé ${ }^{24}(\varepsilon \dot{u} \rho \tilde{v} \theta \mu \omega \varsigma)$ le style qu'il pratique. Cependant, les procédés requis par l'expression périodique reçoivent de la part d'Aristote une autre interprétation que celle d'Isocrate, lequel y voit avant tout des instruments de psychagogie ${ }^{25}$ : ils sont conçus comme des adjuvants de la communication du sens. Grâce à sa structure antithétique, qui rapproche les contraires et favorise, par contraste, leur identification, grâce à la parisose et la paromoïose, qui parachèvent l'équivalence et l'opposition des côlons, grâce enfin au retardement de la compréhension par l'auditeur, aboutissant à une saisie du sens anticipée ou au moins immédiatement complète de la pensée exprimée, la période contribue à la communication du sens et devient la source d'un plaisir ( $\dot{\eta} \delta v ́$ ) philosophique causé par la satisfaction qui succède au relâchement de la tension cognitive ${ }^{26}$.

13 Toutefois, bien qu'Aristote intègre les gorgianismes à sa théorie, le style importe moins dans l'échelle de valeurs philosophique que le fait lui-même: c'est à cause de la médiocrité de l'auditeur que, lié à la question de l'action oratoire, il acquiert un rôle ${ }^{27}$. Aristote reconnait que la manière de dire modifie la signification du contenu, mais ajoute que le style joue essentiellement sur l'imagination et l'oreille de l'auditeur. Aussi remarque-t-il que l'enseignement de la géométrie ne requiert aucun style élaboré, la situation de communication, la visée interlocutive et le contenu du discours n'exigeant pas une expression frappante et harmonieuse.

C'est chez Théophraste que, pour la première fois, le jugement spécifique sur les figures dites gorgianiques peut devenir défavorable. Deux fragments attribués au philosophe guideront notre réflexion. S'ils apportent un éclairage différent, sinon contradictoire, sur les gorgianismes, ne nous en étonnons pas trop: la doctrine rhétorique de Théophraste, reconstituée d'après des témoignages indirects dont l'authenticité est parfois discutée, ne fait l'objet d'aucun consensus de détail en l'absence de sources directes. 

qu'il a approfondis et systématisés, a élaboré une doctrine de l'élocution fondée sur quatre virtutes dicendi. D'après le témoignage de Cicéron $^{28}$, ces qualités sont: 1) la pureté et la correction (sermo purus erit et Latinus) ; 2) la clarté et la netteté (dilucide planeque dicetur) ; 3) la convenance (quid deceat circumspicietur) ; 4) l'ornement plaisant et abondant (ornatum suave et affluens). Ces vertus du style étant nommées, les figures en général contribuent à produire une certaine qualité stylistique complexe, comme nous l'apprend un fragment conservé par Denys d'Halicarnasse :

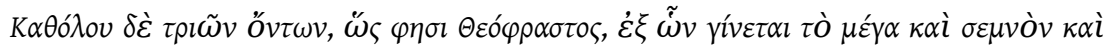

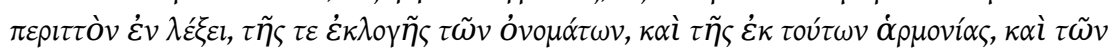

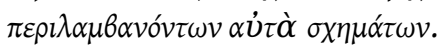

Il y a en tout trois choses, comme le dit Théophraste, qui produisent le grand, le noble et le raffiné dans l'expression, le choix des mots, l'harmonie qu'ils créent et les figures qui les incluent ${ }^{29}$.

Fait remarquable, ce fragment contient, à notre connaissance, la première occurrence plurielle de $\sigma \chi \tilde{\eta} \mu \alpha$ employé à propos du style et à l'exclusion d'une signification renvoyant aux types de preuves ou aux parties du discours. S'il est authentique, il conforte l'hypothèse qui attribue à Théophraste un rôle de promoteur majeur des doctrines des figures ${ }^{30}$.

Toutefois, même ainsi, des incertitudes demeurent. À laquelle des quatre qualités du style générales doit-on, en premier lieu, relier «le grand, le noble et le raffiné dans l'expression »? Si c'est à la quatrième qualité, celle de l'ornement, qu'il parait le plus judicieux de les rapporter, puisque ce sont uniquement les mots en eux-mêmes qui sont considérés, la troisième qualité théophrastienne, celle de la convenance, peut elle aussi requérir, en théorie, une adaptation du style (en fonction de l'objet, du genre, de la partie du discours, de l'expression de l'éthos ou du pathos, etc.) qui se traduira par une exigence de grandeur, de noblesse et de raffinement. En second lieu, quelles sont ces figures qui incluent les mots? Les gorgianismes traditionnels sont-ils compris dans leur nombre? D'après d'autres auteurs comme Démétrios ou Denys lui-même, il semble raisonnable de croire que les figures dites gorgianiques ont dépendu, chez Théophraste, de l'ornement, peut-être de l'une de ses subdivisions, caractérisée par une certaine emphase. Dans ce fragment, aucun jugement négatif ne se laisse deviner. Tout au plus s'avisera-t-on que les gorgianismes sont désormais au service, contrairement à leur fonction chez Aristote, d'une intention esthétique, voire éthique, sur laquelle nous reviendrons. Les conséquences d'un tel changement seront considérables pour les théories à venir.

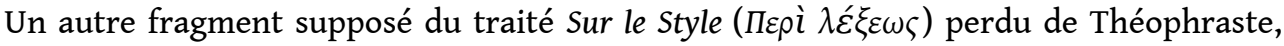
portant sur l'antithèse, sépare clairement ce procédé de ceux qui l'accompagnent traditionnellement dans la prose d'art: la parisose et la paromoïose. Alors que l'antithèse devient un outil pour la pensée, la parisose et la paromoïose sont qualifiées de jeux puérils, un terme que Denys d'Halicarnasse, qui est encore notre source

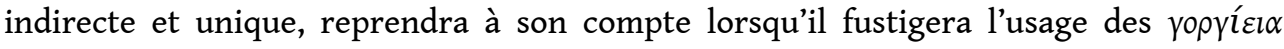
$\sigma \chi \eta ́ \mu \alpha \tau \alpha$ (figures gorgianiques ${ }^{31}$ ) :

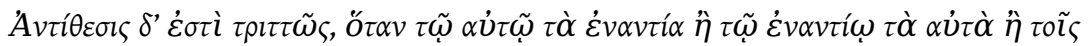

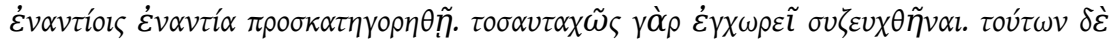

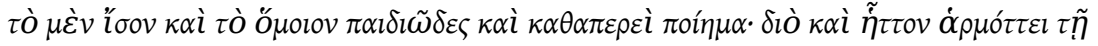

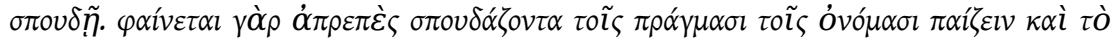

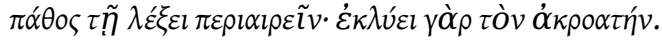


L'antithèse revêt trois formes; les qualités contraires peuvent être attribuées au même objet, ou les mêmes qualités à l'objet contraire, ou des qualités contraires aux objets contraires; ce sont là les seuls rapports possibles. Quant à l'égalité ou la ressemblance de ces éléments, ce sont jeux d'enfants, à l'imitation de la poésie ; c'est pourquoi ils ne s'adaptent guère aux sujets graves. Il paraît en effet peu convenable, pour traiter une matière sérieuse, de jouer avec les mots et de supprimer l'émotion par la manière de l'exprimer : cela distrait l'auditeur ${ }^{32}$.

Dans un article consacré à l'antithèse ${ }^{33}$, nous avons montré que chez Aristote et Théophraste (lequel complète la définition donnée dans la Rhétorique), ce procédé devait être envisagé dans ses rapports avec l'expression de la pensée formalisée par les lieux des enthymèmes, notamment le premier de la liste dressée par Aristote ${ }^{34}$. Ce fragment transmis par Denys d'Halicarnasse ${ }^{35}$ expose ainsi qu'à partir d'une paire de sujets contraires entre eux (par exemple «ami / ennemi ») et d'une paire de prédicats contraires entre eux (par exemple "bénéfique / nuisible »), une antithèse ne saurait s'obtenir que selon trois modalités combinatoires: 1) les prédicats contraires sont attribués conjointement à l'un ou l'autre des sujets;2) l'un ou l'autre prédicat est attribué à l'un et à l'autre des deux sujets contraires ; 3) un prédicat est attribué à un sujet, et le prédicat contraire au sujet contraire. Les deux premières modalités pourront, par exemple, être employées dans des enthymèmes réfutatifs : 1) «il est impossible qu'un ennemi soit nuisible mais aussi bénéfique» ou "il est impossible qu'un ami soit bénéfique mais aussi nuisible »;2) « il est impossible qu'un ami et qu'un ennemi soient bénéfiques » ou "il est impossible qu'un ennemi et qu'un ami soient nuisibles ». La troisième modalité sera utile à la formulation d'un enthymème démonstratif semblable au premier de ceux répertoriés dans la Rhétorique d'Aristote (II, 23) : «puisqu'un ami est bénéfique, un ennemi est nuisible». Comme ces quelques exemples le montrent, Théophraste semble avoir fait de l'antithèse un outil logique de

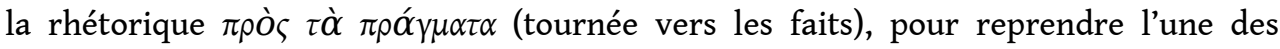
distinctions que, d'après Ammonius ${ }^{36}$, il établit. Quant à l'égalité et à la similitude phonique qui accompagnent traditionnellement l'antithèse, Théophraste les range dans la rhétorique $\pi \rho \grave{\varsigma} \tau o \grave{\nu} \varsigma \dot{\alpha} \kappa \rho \circ \omega \mu \varepsilon ́ v o u \varsigma^{37}$ (tournée vers les auditeurs), puisqu'il les interprète comme des procédés poétiques. Il en nie toutefois la puissance absolue sur l'auditoire et les condamne dans certaines circonstances, quand Lysias, par exemple,

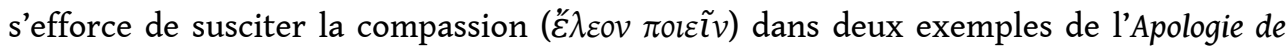
Nicias dont Denys conteste l'authenticité :

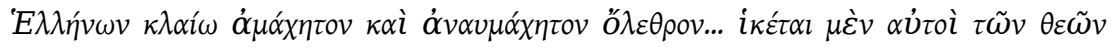

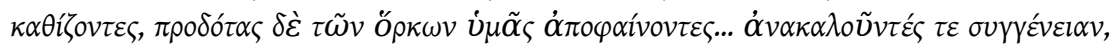

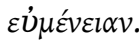

Je pleure le désastre des Grecs advenu sans avoir combattu ni s'être en mer battu... Se posant eux-mêmes comme suppliants des dieux, vous accusant d'être des traittres à vos serments... invoquant parenté, bienveillance ${ }^{38}$.

Tout le passage accumule en effet les gorgianismes. Le premier exemple, une paromoïose parfaite, se compose de deux côlons de neuf syllabes et trois mots marqués

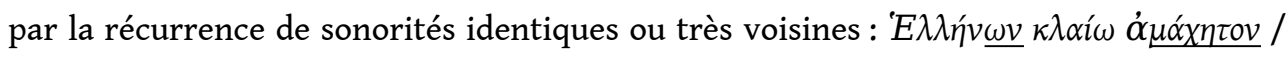

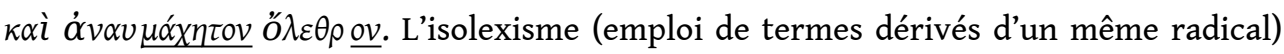

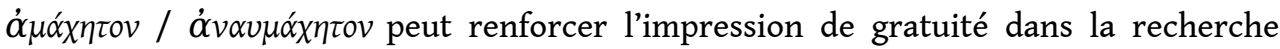

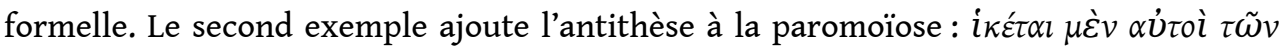

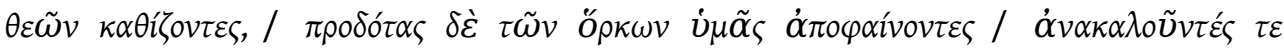

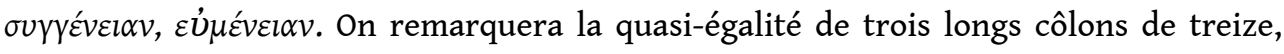
quatorze et quatorze syllabes, l'emploi des particules $\mu \varepsilon^{\prime} v$ / $\delta \dot{\varepsilon}$ (d'une part... d'autre 
part...) qui construisent une antithèse caractérisée par la duplication de la structure

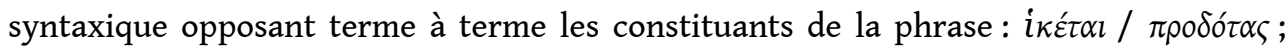

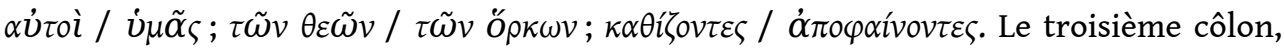
qui paraît être la suite des deux précédents, introduit une variation. Le rappel sonore

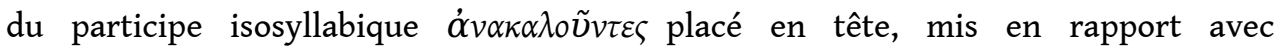

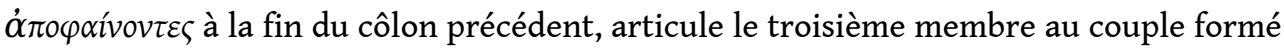
par les deux premiers ; puis, au sein même de ce troisième côlon, une nouvelle parisose

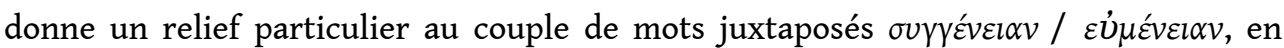
raison de l'égalité syllabique, de la ressemblance sonore, mais aussi de l'asyndète qui juxtapose les deux termes sur un ton vif et véhément. On conçoit aisément, d'après cette brève description des procédés à l'œuvre dans les citations de Lysias, que Théophraste ait pu juger nécessaire de dissocier fermement recherche formelle et expression sincère, par exemple d'après le simple constat que pour paraître sincère, on doit donner l'impression d'être spontané et de ne pas avoir choisi ses mots avec soin et d'après des règles poétiques.

En somme, ce dernier fragment fait état d'une évolution notable de la théorie aristotélicienne sous l'influence de Théophraste. Chez le Stagirite, la convenance entre le contenu et le style, nécessaire à la véridicité supposée du discours dans l'esprit de l'auditeur, concernait surtout l'expression au sens de «choix des mots ${ }^{39}$ ». Chez Théophraste, du moins dans le présent fragment, l'inconvenance entre le contenu et le style devient aussi affaire de $\lambda \hat{\varepsilon} \xi \zeta \zeta$ au sens de «composition »: la période n'est plus seulement considérée comme vecteur de sens, mais comme procédé plaisant à utiliser à bon escient. De l'í $\delta v^{40}$ aristotélicien (le plaisir philosophique), on passe, pour emprunter le mot de Denys explicitant la pensée de Théophraste, au $\chi \alpha \rho i ́ \varepsilon v^{41}$ (le charmant) : la distance parcourue est celle qui sépare le plaisir philosophique de l'âme du simple agrément des sens. Faute de sources précises, nous en sommes réduits à enregistrer l'évolution sans pouvoir en rendre compte de manière satisfaisante. Les critiques de Théophraste, en tout cas, marquent une prise de distance par rapport à Aristote : elles ont pu être liées, dans le cadre des tâches de l'orateur, à la recherche d'une meilleure expression du pathos et de l'éthos, à une plus grande détermination de

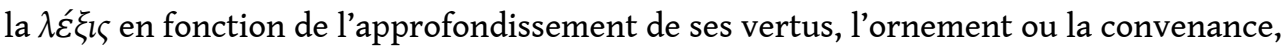
ou du genre oratoire ; elles peuvent avoir été suscitées également par l'activité critique de Théophraste, qu'on voit manifestement à l'œuvre à propos de Lysias. Quant à la valeur esthétique accordée aux $\sigma \chi \eta \dot{\eta} \mu \alpha \tau \alpha$ dans la production du grand, du noble et du raffiné, elle suggère que les $\sigma x \eta ́ n \alpha \tau \alpha$ étaient recommandés dans certaines situations seulement. Nous ne pouvons guère qu'émettre des hypothèses sur cette valeur, mais il semble, d'après les termes qui désignent les qualités stylistiques produites, que l'effet esthétique des $\sigma \chi \eta \dot{\eta} \mu \alpha \tau \alpha$, joint au choix des mots et à leur harmonie, provienne en partie du fait qu'ils reflètent en quelque sorte l'éthos de l'orateur. "Grand", "noble " et " raffiné » se disent en effet du caractère. Ces procédés, employés à contretemps comme dans un appel à la pitié, sonnent faux. On est ainsi obligé d'admettre, au niveau de la $\lambda \hat{\varepsilon} \xi ı \zeta$, une infime fissuration de l'unité du style professée par Aristote et Théophraste, certes restreinte, mais réelle. En vérité, si les gorgianismes correspondent à une variété de l'ornement (le grand, noble et raffiné par opposition à une autre variété qui n'est pas connue), si on leur accorde une valeur non plus cognitive, mais esthétique et éthique en fonction de certaines conditions propices à leur emploi, cela annonce, à terme, l'inévitable éclatement de l'unité du style. 


\section{Rhétorique et gorgianismes : le crédible ou le beau}

21 L'évolution et la diversification des théories, sans doute à partir du III siècle av. J.-C., prouvent que le cadre des tâches de l'orateur fixé durablement par Aristote et Théophraste a pu paraître insuffisant: sous l'effet d'une ambition critique visant la systématisation, d'autres approches ont vu le jour, plus générales, comme les doctrines stylistiques globales, ou plus restreintes, comme celles relatives aux figures. Les recherches des rhéteurs révèlent une certaine instabilité des normes stylistiques après Théophraste. Et pour rendre l'enquête plus difficile, la documentation portant sur les $\mathrm{III}^{\mathrm{e}}-\mathrm{I}^{\mathrm{e}}$ siècles av. J.-C. est très maigre. Deux sources aident cependant à cerner les contours du débat qui pouvait exister sur les figures gorgianiques: le traité de Démétrios $^{42}$ et la Rhétorique à Herennius ${ }^{43}$. Chez ces auteurs, les gorgianismes sont critiqués mais d'une manière qui reste imprécise.

Démétrios élabore une doctrine comportant quatre types stylistiques qui couvrent tout le domaine de la littérature. L'originalité de sa conception, par rapport à Aristote, est

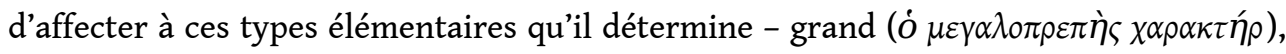

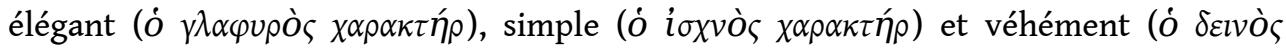

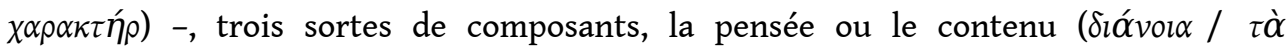

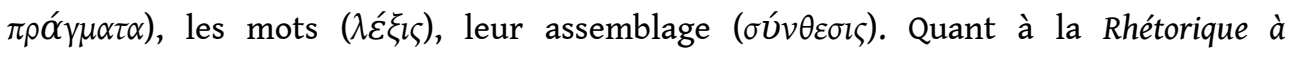
Herennius, elle mentionne pour la première fois la théorie des trois styles (genera dicendi), plus ancienne que le traité latin et attribuée parfois à Théophraste.

La difficulté, pour ces théories, qui empruntent aux travaux antérieurs et en premier lieu à Aristote, est qu'elles doivent organiser avec cohérence les connaissances anciennes en fonction des divisions qu'elles instituent et qui reflètent les nouvelles normes stylistiques. La classe des figures pose justement problème à Démétrios, qui ne la retient pas, remarque Pierre Chiron, à cause des chevauchements qu'elle introduirait d'une rubrique à l'autre, certaines se rattachant à la pensée, d'autres aux mots, d'autres à l'assemblage. De plus, il était difficile à Démétrios d'assigner une place spécifique aux figures dans chaque type de style, les mêmes se retrouvant d'un type à l'autre ${ }^{44}$. Dans la Rhétorique à Herennius, de même, aucune figure en particulier n'est réservée à l'un des trois styles.

24 C'est dans les chapitres 22 à 29 que Démétrios aborde la question des gorgianismes. L'antithèse y reçoit un traitement particulier marqué par l'influence de la Rhétorique à Alexandre et de la Rhétorique d'Aristote, mais, comme nous l'avons remarqué ailleurs ${ }^{45}$, Démétrios interprète l'antithèse verbale dans un sens contraire à celui de la Rhétorique à Alexandre, celui d'une correspondance terme à terme des mots opposés par un

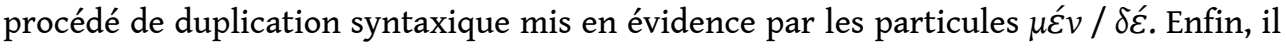
regroupe sous le nom de paromoïose la ressemblance des côlons au début et à la fin et l'isocôlie. L'homéotéleute est présentée comme une subdivision de la paromoïose.

25 Concernant l'emploi de ces procédés, l'auteur condamne ensemble l'emploi de l'antithèse, la similitude et la paromoïose dans le style véhément ${ }^{46}$, car ils nuisent à l'expression du pathos et de l'éthos ${ }^{47}$, et doivent donc être évités dans l'exorde et la péroraison. Démétrios dénonce enfin l'incompatibilité d'un tel style avec certaines circonstances et rapproche l'emploi inopportun des gorgianismes d'expressions comme " rire mouillé de larmes », ou de proverbes comme " rire aux enterrements ${ }^{48}$ ». 
26 Le grand style, toutefois, peut requérir l'utilisation des gorgianismes, comme chez Isocrate et Gorgias, ainsi que le style plaisant, lorsque les gorgianismes sont employés " au second degré ${ }^{49}$ ». Démétrios, pour donner un exemple, cite un trait d'esprit d'Aristote :

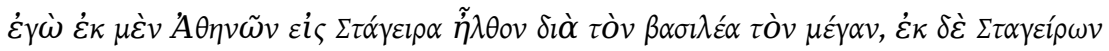

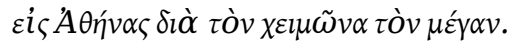

Je suis allé d'Athènes à Stagire à cause du Grand Roi, et de Stagire à Athènes à cause du grand froid ${ }^{50}$.

L'auteur affirme ainsi une incompatibilité entre, d'un côté, la beauté formelle, l'expression recherchée, et de l'autre sa crédibilité. Si les gorgianismes peuvent concourir au grand style, les conditions de leur apparition restent incertaines. Démétrios a beau restreindre prudemment leur emploi au grand style imité d'Isocrate et Gorgias (une précision de la plus haute importance car l'austérité, qualité contraire, est aussi une caractéristique du grand style), puisque " tous les types se mélangent ${ }^{51}$ " dans le tissu d'un discours réel, les situations où les gorgianismes seront condamnables ou recommandables ne sont pas clairement identifiées, à l'exception du style véhément, du pathos et de l'éthos, voire de l'humour, nommément cités.

Quant à l'auteur de la Rhétorique à Herennius, il critique les gorgianismes et tente cependant de rationaliser leur utilisation :

Quomodo igitur, si crebro his generibus utemur, puerili videbimur elocutione delectari; item, si raro interseremus has exornationes et in causa tota varie dispergemus, commode luminibus distinctis inlustrabimus orationem.

Autant, donc, si nous employons ces espèces (sc. de figures) de manière répétée, nous semblerons nous complaire à un style puéril (sc. affecté), autant, si nous introduisons rarement ces figures et que nous les dispersons avec variété dans toute la cause, nous conférerons comme il convient, au moyen de traits brillants espacés, de l'éclat au discours ${ }^{52}$.

Exception et variété de la formulation - ce dernier point mériterait plus de précision seraient par conséquent les règles qui permettraient d'utiliser au mieux les gorgianismes.

Ce que nous retiendrons, en tout état de cause, de l'examen des deux rhéteurs, est que leurs réserves révèlent a posteriori une certaine fragilité de la théorie stylistique aristotélicienne, qui, postulant, au moins en principe, l'unité d'un style adapté à une rhétorique démonstrative et rationnelle, n'a pas pu nier une interprétation des procédés dits gorgianiques en termes d'esthétique ni n'a su éviter la division du style aristotélicien en une pluralité de styles divers. La critique théophrastienne semble avoir contribué à pointer l'insuffisance de la théorie en dénonçant une incompatibilité entre un style recherché et telle situation donnée caractérisée par le sujet, la partie du discours (exorde, péroraison) concernée et le type de preuve utilisé (éthos, pathos). Une redistribution du matériau rhétorique préexistant semble avoir eu lieu. Malgré la rareté des sources, on devine que les gorgianismes ont été jugés comme relevant d'une division particulière de l'ornement et réservés à l'expression recherchée. Les flottements terminologiques laissent percevoir des enjeux liés à la définition de styles pouvant couvrir le champ de la littérature, et, dans le seul domaine oratoire, à la définition de styles organisés par groupe de trois. Les gorgianismes, dans ces théories, ne s'intègrent pas parfaitement dans la détermination d'un style particulier ( $L a$ Rhétorique à Herennius les prescrit dans les trois styles), et la méfiance de Démétrios prolonge l'analyse théophrastienne limitée aux tâches de l'orateur. De plus, ces styles particuliers ne définissent jamais un champ précis de la littérature. On retire donc 
finalement une impression d'incomplétude des travaux qui ont suivi ceux de Théophraste.

\section{Critique littéraire et gorgianismes : vraie beauté contre fausse beauté}

Dans la seconde moitié du $\mathrm{I}^{\mathrm{er}}$ siècle av. J.-C., l'œuvre de Denys d'Halicarnasse représente un tournant dans la perception des figures associées avant lui à la beauté et à l'élégance du discours. Son activité de critique littéraire l'engage dans la défense de l'éloquence attique contre les excès de l'asianisme ${ }^{53}$, et, s'il s'inspire de prédécesseurs pour formuler ses points de vue en matière de style, notamment Théophraste, sa théorie a sa propre originalité, dans la mesure où il utilise librement les schémas traditionnels. Denys assigne à ses analyses une visée descriptive et normative. Il s'agit de reconnaître les meilleurs auteurs et ce qu'il y a de meilleur en eux, et, pour l'homme qui cultive l'éloquence, d'imiter les qualités et d'éviter les défauts de ses modèles ${ }^{54}$. En la matière, Démosthène devient pour Denys le modèle de la meilleure éloquence ${ }^{55}$.

La théorie de Denys se fonde dans une certaine mesure sur des considérations d'ordre historique: il reconnaît une évolution du style liée aux temps, aux lieux, aux

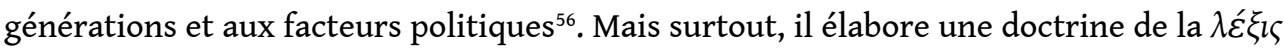
inspirée d'Aristote et de Théophraste fondée sur l'examen des éléments remarquables de la $\lambda \hat{\varepsilon} \xi_{\imath \zeta}$ et de ses différentes qualités ( $\left.\dot{\alpha} \rho \varepsilon \tau \alpha i ́\right)$, les unes nécessaires ( $\left.\dot{\alpha} v \alpha \gamma \kappa \alpha \tilde{l} \alpha l\right)$, les

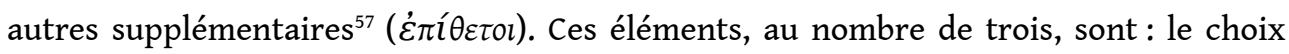

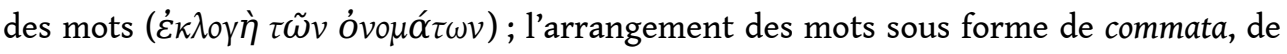
côlons et de périodes $(\sigma v ́ v \theta \varepsilon \sigma l \varsigma \tau \tilde{\omega} v$ óvouó $\tau \omega v)$; les figures données à ces éléments ${ }^{58}$ $(\sigma x \eta ́ \eta \alpha \tau \alpha)$.

31 En outre, Denys fait appel à la doctrine des genera dicendi ${ }^{59}(\alpha \alpha \rho \alpha \kappa \tau \tilde{\eta} \rho \varepsilon \varsigma \tau \tilde{\eta} \varsigma \lambda \lambda \dot{\varepsilon} \xi \varepsilon \omega \varsigma)$, une théorie organisée selon un modèle ternaire qui oppose trois styles, deux extrêmes, le

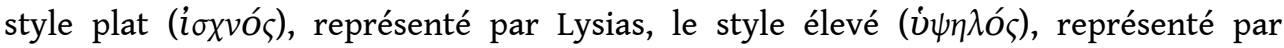

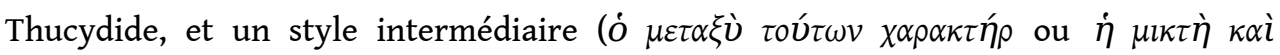

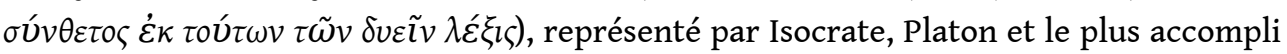
de tous, Démosthène ${ }^{60}$. Pour Denys, la $\lambda \varepsilon^{\prime} \xi \zeta$ n'est pas une, comme elle pouvait l'être aux yeux de Théophraste: identifier trois types sert à classer les auteurs en fonction du type dominant qu'ils illustrent, et suppose une esthétique en fonction de laquelle on les jugera.

32 À la théorie des genera dicendi, Denys ajoute enfin une théorie des genera compositionis. Formée sur le modèle de la précédente ${ }^{61}$, celle-ci approfondit l'un des trois éléments

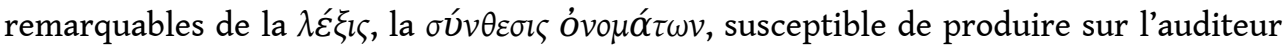
une séduction irrésistible d'ordre purement irrationnel. Cette théorie des genera compositionis, décrite dans la deuxième partie du Démosthène, distingue une composition austère ( $\sigma \dot{v} v \theta \varepsilon \sigma l \varsigma \alpha \dot{v} \sigma \tau \eta \rho \alpha ́)$, produisant le beau ( $\tau \grave{o} \kappa \alpha \lambda o ́ v)$, une composition ciselée ( $\sigma \dot{v} v \theta \varepsilon \sigma l \varsigma \zeta \lambda \alpha \varphi v \rho \rho \alpha ́)$, produisant le plaisant ( $\tau \dot{o} \dot{\eta} \delta u ́$ ), et une composition moyenne

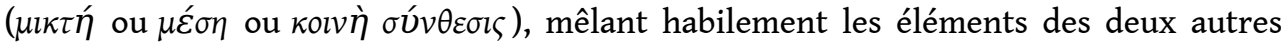
compositions selon les sujets, les parties du discours et les circonstances. Chaque $\sigma u ́ v \theta \varepsilon \sigma \iota \zeta$, exposée dans le Démosthène, reprend partiellement les éléments remarquables de la $\lambda \varepsilon^{\prime} \xi_{l \varsigma}$ : choix des mots selon leur nature phonémique; arrangement des mots en côlons assemblés ou non en périodes ; figures telles que parisose, paromoïose, antithèse 
ou ce qui s'y oppose: ruptures et asymétries. Chaque composition dépend ainsi d'une certaine combinaison des trois éléments remarquables de la $\lambda \varepsilon^{\prime} \xi \zeta$. Ce qui est nouveau chez Denys est qu'il distingue fermement le beau, produit par le style austère, et le plaisant, produit par le style ciselé. Ce choix n'est pas sans conséquence et traduit bien les options esthétiques de Denys contre une conception trop ornementale et formelle de l'expression. Démétrios associait Isocrate à la grandeur du style, ce que refuse Denys, qui choisit Thucydide pour le représenter. C'est ainsi que les figures gorgianiques évidentes et fréquentes, alliées au souci permanent d'euphonie, deviennent chez notre critique le signe d'une éloquence trop maniérée, comme celle d'Isocrate, à laquelle fait écho l'éloquence corrompue des asianistes.

Dans la perspective qui est la sienne, Denys associe les figures gorgianiques, expression qu'il a vraisemblablement forgée ${ }^{62}$, aux échecs des meilleurs auteurs, soit qu'ils désirent pallier la pauvreté des idées, comme il peut arriver à Platon, soit qu'ils accordent trop de soin à la recherche formelle. C'est dans le Démosthène qu'il dresse l'inventaire le plus complet des figures gorgianiques, quoiqu'il affirme qu'il en existe beaucoup d'autres : parisose, paromoïose, antithèse, paronomase, antistrophe, épanaphore ${ }^{63}$.

Isocrate représente pour Denys le meilleur auteur dans sa catégorie, la composition ciselée, mais c'est un auteur qui pèche par excès de soin :

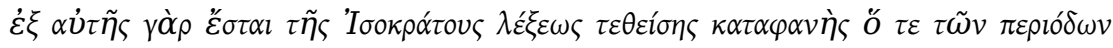

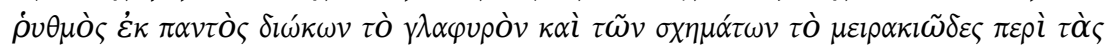

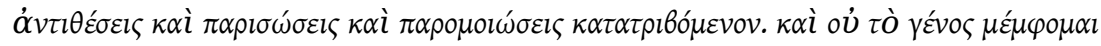

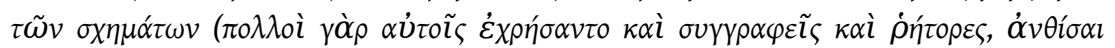

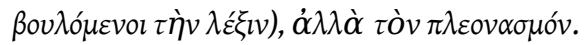

À partir de l'observation du style même d'Isocrate, il sera clair que le rythme de ses périodes cherche à atteindre en toute occasion le style ciselé et que la puérilité de ses figures roule sans cesse sur les antithèses, les parisoses et les paromoïoses. Je ne blâme pas la classe des figures (de nombreux écrivains et orateurs y ont eu recours pour fleurir leur style), mais qu'on en use à l'excès ${ }^{64}$.

La puérilité ou du moins la jeunesse sont souvent associées à l'emploi des figures

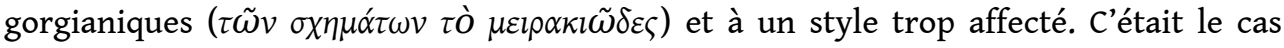
chez Théophraste et dans la Rhétorique à Herennius, et c'est aussi le cas chez Démétrios ${ }^{65}$ et Cicéron ${ }^{66}$. Denys suit donc ici une tradition ancienne. Bien que l'idée ne soit pas exprimée explicitement, il semble qu'un parallèle ait été établi, par Cicéron et Denys, entre les différents stades de l'art oratoire et les âges de l'orateur. Tout comme il fustige la puérilité des figures gorgianiques, Denys reproche aux rhéteurs qui avaient précédé Lysias leur goût pour les tours poétiques et le style représenté par Gorgias ${ }^{67}$. Cicéron pousse plus loin la comparaison : le style asiatique correspond naturellement à l'orateur jeune et au jeune public, en raison d'un intérêt qui s'attache davantage à l'expression qu'à la pensée. Son jugement n'est pourtant pas négatif. Chez Denys, au contraire, c'est toujours à une esthétique dépassée, périmée et inconvenante que renvoient les figures gorgianiques. Elles paraissent n'être qu'un instrument conçu pour le jugement littéraire, mais fournissent dans les faits une arme dirigée contre l'asianisme.

Étant donné que la composition mixte de Démosthène emprunte à la composition austère et ciselée, le style de celui-ci recourt parfois aux figures gorgianiques. Denys ne les exclut donc pas absolument :

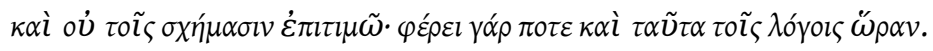


Je ne condamne pas les figures : elles aussi confèrent à l'occasion de la grâce aux paroles ${ }^{68}$.

C'est ce qui explique que, dans le discours, des éléments de la composition austère voisinent avec ceux de la composition ciselée :

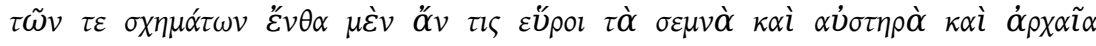

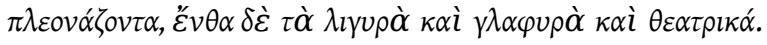

Parmi les figures, on trouvera ici celles qui sont nobles, austères et antiques en très grand nombre, et là celles qui sont douces, ciselées et théâtrales ${ }^{69}$. paromoïose ? En premier lieu que les traités de rhétorique ont insisté très tôt, dès le IV siècle av. J.-C., sur un besoin d'élégance et de beauté formelle, et qu'ils ont indiqué avec une remarquable constance au long des siècles les mêmes moyens de les obtenir grâce à des procédés attribués plus tard par la tradition au sophiste Gorgias. L'histoire de ces procédés témoigne également d'efforts continuels destinés à en légitimer un emploi ponctuel excluant sévèrement leur extension à tous les genres oratoires et toutes les parties du discours. Qualifiés de brillants par Isocrate, ces procédés ont été mutatis mutandis adaptés par Aristote qui leur a conféré une fonction cognitive. Sous le chef de la période, le philosophe a intégré la parisose et la paromoïose à une structure associant étroitement sens et forme. Après lui, la situation a changé. Séparées d'une pensée logiquement construite, parisose et paromoïose n'ont plus été vues que comme de simples ornements. Les rhéteurs n'ont d'ailleurs pas manqué de reconnaître le danger d'y recourir sans mesure : c'est, en substance, le choix de la crédibilité ou de la beauté produite par les procédés poétiques. Avec Denys, nous sommes entrés dans le domaine de la critique littéraire, à une période où une nouvelle esthétique atticisante érigeait Démosthène en modèle. Denys rejetait l'emploi des figures élégantes, caractéristiques des premiers temps de l'éloquence en Grèce et de la dictio Asiatica. Comme nous allons le voir maintenant, la position d'Hermogène est tout empreinte des considérations de ses prédécesseurs mais aussi novatrice.

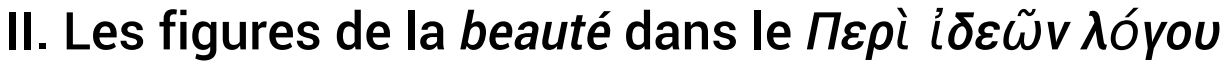 du rhéteur Hermogène}

$\mathrm{Au}$ sein de la théorie des catégories stylistiques, que nous présenterons dans un premier temps, la conception des figures de la beauté d'Hermogène est nuancée mais sûre : au lieu de condamner leur emploi, ce rhéteur les définit précisément et indique

Exercices de rhétorique, 15 | 2020 
avec minutie quand et comment y recourir. Cette théorie, qu'Hermogène a portée à son sommet, est apparue au $\mathrm{II}^{\mathrm{e}}$ siècle de notre ère. Elle a des origines complexes et obscures. Les travaux de Michel Patillon ${ }^{72}$ nous permettent d'en dégager quelques caractères fondamentaux. Il s'agit d'une doctrine synthétique qui, tâchant d'intégrer tous les éléments stylistiques mis à sa disposition par la critique littéraire dans la définition des aspects généraux du style, s'appuie sur cette connaissance pour déterminer l'exacte combinaison des composants du style propre à chaque genre de discours. Hermogène diffère de ses devanciers, Denys de Milet et Basilikos ${ }^{73}$, par un niveau d'analyse bien supérieur : il distingue jusqu'à huit composants ${ }^{74}$ entrant dans la définition de vingt catégories stylistiques.

\section{Le système hermogénien}

Le traité d'Hermogène sur le style se présente comme destiné à l'orateur, mais c'est aussi un ouvrage critique couvrant tout le champ de la littérature. Pour devenir soimême "un artisan de beaux et excellents discours ${ }^{75}$ ", il est nécessaire de pratiquer l'imitation raisonnée de bons modèles, c'est-à-dire de posséder une connaissance approfondie des éléments qui composent les styles individuels de chaque auteur, de savoir précisément ce qu'il faut imiter chez eux et comment le faire : tels sont, en

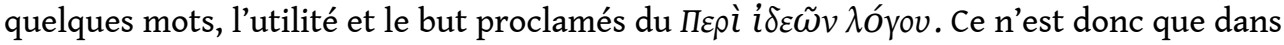
un second temps qu'Hermogène aborde les styles individuels des auteurs, lesquels sont classés en trois genres couvrant tout le champ de la littérature : discours politique (délibératif, judiciaire), discours panégyrique en prose, discours panégyrique en vers. Toutefois, c'est à travers Démosthène et chez lui qu'il faut, selon Hermogène, étudier les éléments du style, parce que cet orateur a plus que les autres diversifié son discours et qu'il les a presque tous employés. Ce n'est donc pas comme d'un style individuel qu'Hermogène traite du discours démosthénien, mais comme d'un discours qui présente, combinés et mélangés de la meilleure manière, la quasi-totalité des éléments qui composent à la fois le discours politique et le discours panégyrique en prose et en vers. Ces « éléments ${ }^{76}$ » qui forment les styles individuels de chaque auteur, Hermogène les nomme catégories stylistiques ${ }^{77}$ ( $i \delta \varepsilon ́ \alpha_{l}$ ), et il consacre la majeure partie de son traité $^{78}$ à exposer ce qu'elles sont et comment on les obtient dans l'ordre suivant : au nombre de sept pour les principales, ce sont la clarté, la grandeur, la beauté, la vivacité, l'éthos, la sincérité et l'habileté. Chaque catégorie est analysée d'après ses huit composants possibles énumérés dans l'ordre de leur importance relative : 1) la pensée, 2) la méthode à propos de la pensée, 3) l'expression, 4) les figures, 5) les côlons, 6) l'assemblage, 7) les pauses, 8) le rythme ${ }^{79}$.

L'ordre de présentation des sept catégories n'est pas indifférent. Les quatre premières, nécessaires au discours dans la mesure où leur contraire est un vice, clarté, grandeur, beauté et vivacité, s'équilibrent l'une l'autre. La clarté, contraire à l'obscurité, est la catégorie première et principale d'un point de vue rhétorique, et, de ce fait, est placée en tête de liste, mais, voisine de la vulgarité si elle est extrême, elle doit être compensée par la grandeur. La grandeur, opposée à la vulgarité, doit elle-même être adoucie par la beauté, pour ne pas rebuter l'auditeur par trop d'âpreté. Enfin, la beauté, dont l'opposé est le négligé, doit être à son tour combattue par la vivacité, au risque de confiner à la nonchalance et à la platitude. L'éthos et la sincérité, en tant que catégories stylistiques, sont qualifiés de très utiles à tout le discours ou seulement partiellement. Enfin, dans la 
mesure où elle consiste en l'exploitation adéquate de toutes les autres catégories, l'habileté vient en dernier.

Treize catégories supplémentaires, tenant un rang second par rapport aux sept principales, constituent certaines d'entre elles : la clarté, la grandeur et l'éthos. Il existe, dans le cas de la clarté et de la grandeur, entre les premières et les secondes un rapport de genre à espèce, puisque le caractère principal des catégories de premier rang se retrouve toujours dans celles de second rang, mais qu'entre elles, les catégories de second rang diffèrent par quelque point. Le statut de l'éthos est plus complexe. Michel Patillon observe que l'éthos et la sincérité se recouvrent partiellement, et qu'à ce titre, ces catégories forment dans les principales une espèce à part ${ }^{80}$. En effet, le discours sincère et spontané est présenté comme un des constituants de l'éthos, qu'il concourt à produire, mais la sincérité a également le statut de catégorie principale. Cela est dû au fait qu'Hermogène traite, dans sa leçon sur l'éthos, de la sincérité en envisageant les textes dans leur aspect sincère et éthique. Le schéma suivant permet de prendre brièvement connaissance des catégories de second rang et de leur rapport aux catégories principales. 


\begin{tabular}{|c|c|c|c|}
\hline \multicolumn{2}{|l|}{ Catégories de second rang spécifiques } & $\begin{array}{l}\text { Catégories } \\
\text { premier } \\
\text { génériques }\end{array}$ & $\begin{array}{r}\text { de } \\
\text { rang }\end{array}$ \\
\hline \multicolumn{2}{|l|}{ 1) Pureté (opposée de l'expansion) } & \multirow{2}{*}{ Clarté } & \\
\hline \multicolumn{2}{|l|}{ 2) Netteté (opposée de la confusion) } & & \\
\hline \multicolumn{2}{|l|}{ 3) Noblesse (opposée de la naïveté) } & \multirow{6}{*}{ Grandeur } & \\
\hline \multicolumn{2}{|l|}{ 4) Expansion (opposée de la pureté) } & & \\
\hline \multicolumn{2}{|l|}{ 5) Rudesse (opposée de la saveur et de la modération) } & & \\
\hline \multicolumn{2}{|c|}{ 6) Éclat (opposée de la vivacité, du style commatique et dialogué) } & & \\
\hline \multicolumn{2}{|c|}{$\begin{array}{l}\text { 7) Vigueur (opposée de la saveur et de la modération pour la pensée ; } \\
\text { opposée du style commatique, dialogué et vif) }\end{array}$} & & \\
\hline \multicolumn{2}{|l|}{ 8) Véhémence (opposée de la saveur et de la modération) } & & \\
\hline $\begin{array}{l}\text { 10) La saveur (opposée de la rudesse, la vigueur et de } \\
\text { la véhémence), présentée comme intensification de } \\
\text { la naïveté. }\end{array}$ & $\begin{array}{l}\text { 9) Naïveté (opposée } \\
\text { de la noblesse) }\end{array}$ & \multirow{4}{*}{\multicolumn{2}{|c|}{ Éthos }} \\
\hline 11) Le piquant & & & \\
\hline \multicolumn{2}{|c|}{ 12) Modération (opposée de la rudesse, la vigueur et la véhémence) } & & \\
\hline $\begin{array}{l}\text { 13) Sévérité (qui ne se rencontre pas en elle-m } \\
\text { constitution de laquelle entrent la modération, la } \\
\text { autres espèces de l'éthos) }\end{array}$ & $\begin{array}{l}\text { lême, mais dans la } \\
\text { naïveté ou une des }\end{array}$ & & \\
\hline
\end{tabular}

Quant aux autres catégories principales, elles se répartissent en deux groupes. La beauté, la vivacité et l'habileté subsistent par elles-mêmes, c'est-à-dire ne sont constituées par aucune catégorie de second rang et ne partagent rien qui soit emprunté à d'autres catégories.

Après avoir exposé les éléments du style, Hermogène en vient aux styles individuels, jugés d'après le mélange des éléments qui composent les trois sortes de discours. Dans le discours politique, Démosthène est l'orateur qui a utilisé le meilleur mélange des éléments : le discours politique le plus beau, celui qui réalise le meilleur mélange des éléments, est le discours démosthénien, vu comme une moyenne entre le discours démosthénien délibératif et le discours démosthénien judiciaire. Dans le discours panégyrique en prose, Platon est jugé le meilleur auteur. Dans le discours panégyrique en vers, c'est Homère qui reçoit cette distinction. 


\section{Les figures de la beauté chez Hermogène} examen des figures de la beauté chez cet auteur modèle est donc capital. Pour commencer, Hermogène distingue deux sortes de beauté. Une première, qui peut concerner toute catégorie stylistique, provient, si l'on examine un composant, de l'heureuse combinaison et de la juste proportion de ses constituants ${ }^{81}$. Cette beauté s'accompagne d'une certaine qualité d'éthos ${ }^{82}$, une expression qu'Hermogène ne précise guère, comparée à la couleur unique d'un corps perceptible tout au long du discours. Cette couleur sera produite tout aussi bien dans l'emploi des catégories séparément que dans leur mise en œuvre commune dans le discours démosthénien. Malgré ces indications, Hermogène ne dit rien des moyens grâce auxquels sera obtenue cette couleur, qui devra, précise-t-il, convenir aux catégories employées.

Cette comparaison du discours à un corps humain bien proportionné et d'un beau teint se poursuit lorsque Hermogène expose sa conception de la catégorie stylistique de la beauté. Par contraste, cette seconde sorte de beauté, additionnelle, est présentée comme un ornement plaqué de l'extérieur sur le discours. Elle équivaut à une parure, comme le souligne la synthèse de Michel Patillon : Hermogène parle de visée esthétique claire, de dessein et de recherche manifestes, d'éléments clairement distincts, d'ornement voyant et d'embellissement clairement montrés ${ }^{83}$. Le terme d'élégance

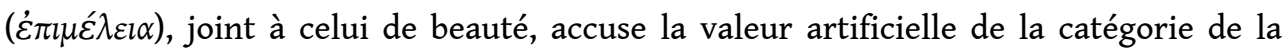
beauté opposée à celle naturelle produite par l'heureux mélange des autres catégories. De telles comparaisons n'ont rien de gratuit mais se fondent sur une analyse rigoureuse d'Hermogène en accord avec les réflexions du Ps.-Longin sur l'arrangement des mots au chapitre 28 du Traité du sublime. Tout en reconnaissant la nécessité d'une composition périodique, ce rhéteur met en garde contre un arrangement trop recherché des périodes, un véritable vice qui affaiblit le discours et détruit le sublime constitué par des éléments naturels - la pensée et la passion-, et par des éléments techniques - les figures, l'expression et l'arrangement.

Les figures de la beauté prennent place dans l'exposé à titre de composants de cette catégorie. Fait frappant, la beauté ne comprend aucun composant relevant du contenu (pensée, méthode à propos de la pensée) : prenant pour seul matériau le signifiant, elle est traitée dans une perspective purement esthétique, au sens où rien de noétique ne participe de cette beauté. La comparaison établie par Hermogène entre la catégorie de la beauté et l'ornement extérieur est donc parfaitement motivée. Cette conception esthétique inscrit indéniablement Hermogène dans la tradition des figures dites gorgianiques, représentée chez Hermogène par Isocrate, qu'il convoque à titre d'exemple pour l'opposer à Démosthène. C'est aussi, plus particulièrement, la théorie des virtutes dicendi remontant à Théophraste que la doctrine hermogénienne évoque où, dans la théorie des tâches de l'orateur, l'elocutio vise à l'ornement qui, destiné à plaire, « doit renforcer la puissance qu'exerce l'argumentation sur la pensée, par la puissance qu'exerce le plaisir sur l'âme ${ }^{84} »$. Comme on va le voir, Hermogène adopte une position très originale face à la difficulté technique que constitue l'emploi des figures dites gorgianiques : comment en user au mieux, en tenant compte des risques élevés que leur mauvaise utilisation comporte? Il suffit d'en atténuer, sans pour autant la faire disparaître, l'impression qu'elles produisent sur l'auditeur : " Démosthène emploie les

Exercices de rhétorique, 15 | 2020 


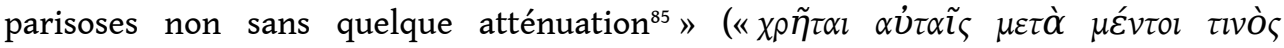
$\pi \alpha \rho \alpha \mu v \theta i ́ \alpha \varsigma »)$.

Tout comme Isocrate, Démosthène fait en effet lui aussi grand usage des figures de la beauté. Il faut donc en traiter, déclare Hermogène, puisqu'il s'agit d'une catégorie stylistique employée dans le discours démosthénien. Ces figures sont les parisoses de début et de fin (homéotéleute), les parisoses par côlon entier, les épanaphores, les antistrophes, les épanastrophes, les gradations, les distributions avec appariement, les hyperbates par transposition, les figures inhabituelles, les affirmations au moyen d'une double négation, et enfin les figures polyptotes. Parmi ces procédés, certaines figures se prêtent à une forme d'atténuation : la parisose, la parisose par côlon entier.

Démosthène emploie très rarement des parisoses semblables à celles d'Isocrate. Le début du Contre Androtion constitue pour Hermogène un cas unique :

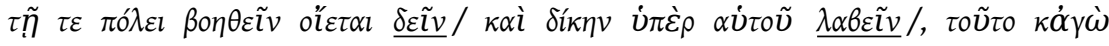

$\pi \varepsilon l \rho \alpha ́ \sigma o \mu \alpha l ~ \pi o l \varepsilon \tilde{\varepsilon} v$.

D'apporter à l'État sa collaboration, il se fait une obligation, et d'obtenir pour lui-

même réparation; et ce sera aussi mon ambition ${ }^{86}$.

Syrianus, un commentateur d'Hermogène, note que les trois côlons, presque isosyllabiques, se terminent de manière identique (homéocatalectiques), et recourent à un assemblage pur sans hiatus et avec des pauses qui finissent sur des mots plutôt courts $^{87}$. Un autre exégète anonyme ajoute que Démosthène veut surpasser un élève d'Isocrate, Androtion, pour plaire au public ${ }^{88}$, et une scolie renvoie à Démosthène luimême, qui dit qu'Androtion est un spécialiste du discours ${ }^{89}$. En règle générale, cependant, Démosthène atténue ses parisoses de trois manières : 1) l'interruption au moyen d'insertions, 2) le déplacement des syllabes qui produisent la parisose, 3) la parisose par côlon entier.

51 Michel Patillon souligne la parenté de l'analyse hermogénienne avec l'analyse moderne de Jakobson sur la fonction poétique du langage ${ }^{90}$. Jakobson caractérise la fonction poétique par la projection du principe d'équivalence de l'axe paradigmatique sur l'axe syntagmatique. En substance, la fonction poétique postule, sur le plan phonique, la mise en équivalence de chaque syllabe, de chaque more (unité phonologique constituant seule ou combinée les syllabes) et de chaque accent d'une séquence avec les autres syllabes, les autres mores et les autres accents de cette séquence. Cette équivalence est ce qui fonde la commensurabilité des séquences phoniques de la chaîne parlée. Répétitions et variations provoquent l'émergence par contraste des structures phoniques, lesquelles constituent le langage en objet poétique ${ }^{91}$. Dans les parisoses hermogéniennes atténuées, les procédés mis en œuvre ont pour but de brouiller le processus opéré par l'équation poétique et d'empêcher partiellement la perception par l'auditeur d'une recherche formelle trop voyante de côlon à côlon.

L'interruption avec insertion consiste à disjoindre les côlons qui se répondraient par une longueur semblable et des sonorités répétées :

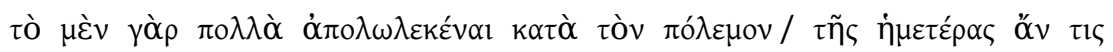

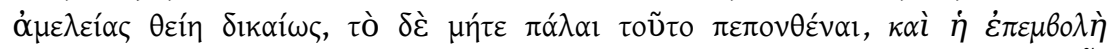

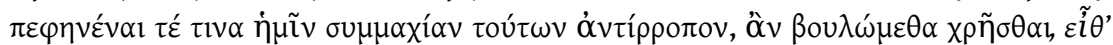

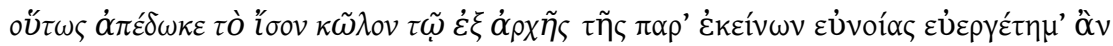
ह̌ $ү \omega \gamma \varepsilon \theta \varepsilon i ́ n v$.

Que, d'un côté, nous ayons subi de nombreuses pertes pendant la guerre, il serait juste de le mettre au compte de notre négligence, que, de l'autre, nous ne les ayons pas subies plus tôt, puis l'insertion: et que vienne s'offrir à nous une alliance qui les compensera, si nous 
voulons la saisir, et ensuite seulement l'apodose du côlon pareil à celui du début : j’y

verrais pour ma part un bienfait à mettre au compte de leur bienveillance ${ }^{92}$.

Les correspondances sonores (allitérations et assonances, rimes internes) et les

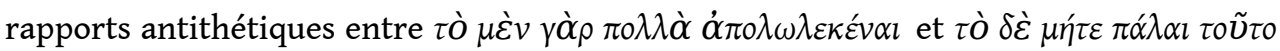

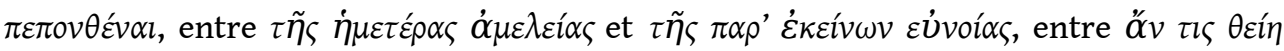

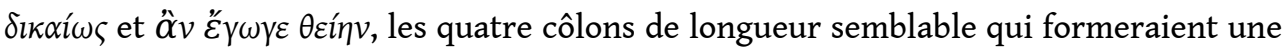
période carrée, tout cela est atténué par une longue insertion qui rend plus difficile la perception des rapports entre les mots.

De la même manière, Démosthène modifie la place des mots qui produiraient une parisose :

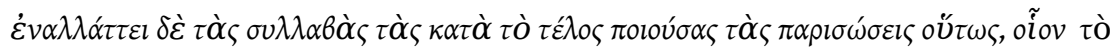

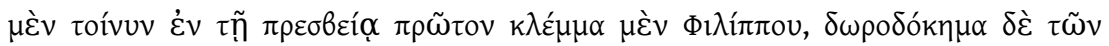

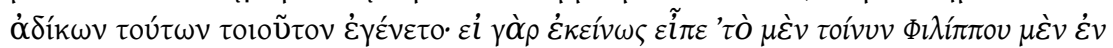

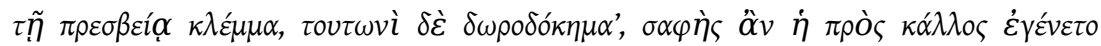

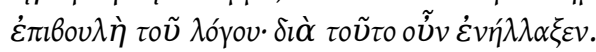

Et voici comment il déplace les syllabes qui, placées à la fin, engendrent une parisose : tel fut donc dans l'affaire de l'ambassade le premier acte de duplicité de Philippe et le premier acte de vénalité de ces criminels : car s'il avait dit : du côté de Philippe, donc dans les affaires de l'ambassade, la duplicité, et du côté de ces individus, la vénalité, le dessein esthétique de l'énoncé eût été clair ; d'où ce déplacement ${ }^{93}$.

Démosthène use enfin, selon Hermogène, d'un dernier artifice pour rendre ses parisoses par côlon entier moins voyantes. Ce ne sont plus des sonorités identiques qui sont considérées ici, mais un nombre de syllabes égal d'un côlon à l'autre. Hermogène remarque que Démosthène emploie aussi ce genre de parisose mais de manière incomplète :

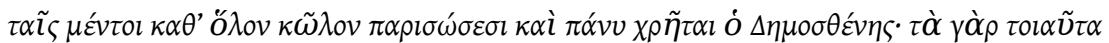

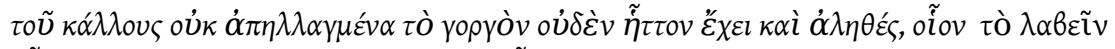

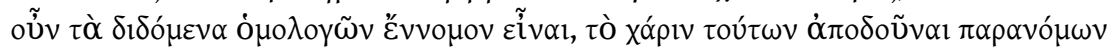

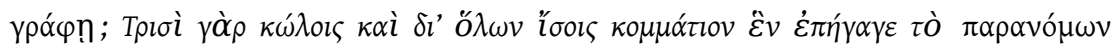

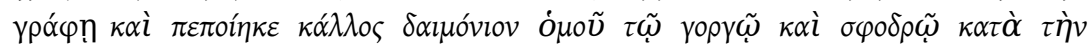

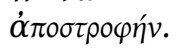

Quant aux parisoses par côlon entier, Démosthène en use, et même largement; de tels énoncés en effet, sans cesser d'être beaux, n'en ont pas moins de vivacité et de sincérité, par exemple : ainsi donc l'acceptation des dons, tu la reconnais comme légale, et la gratitude qu'on en a, tu l'accuses de crime? À trois côlons dans leur entier pareils il a ajouté un petit comma : tu l'accuses de crime et il a produit une merveilleuse beauté en même temps que de la vivacité, et aussi de la véhémence dans l'apostrophe ${ }^{94}$.

L'analyse hermogénienne de cet exemple est complexe: d'une part la beauté est masquée par l'incomplétude syllabique du système carré de cette période, on pourrait ajouter aussi par l'absence de parisose fondée sur les sonorités ; d'autre part, la beauté, qui court toujours le risque d'apparaître comme nonchalante et plate pour Hermogène, est tempérée par la brièveté des côlons, qui confère à l'énoncé de la vivacité, et par l'apostrophe interrogative qui lui donne de la véhémence. C'est ainsi que Démosthène réussit, selon les mots d'Hermogène, le plus parfait mélange des catégories stylistiques et de leurs composants dans un même énoncé.

Au-delà de l'heureux mélange des catégories stylistiques et de la nécessité de ne pas céder à la tentation d'une recherche purement formelle représentant un risque pour la sincérité et la crédibilité du discours, Hermogène a réfléchi à une fonction de la beauté au niveau de l'expressivité, mais il sépare cette question de son exposé sur la catégorie de la beauté. Il se borne à remarquer que l'épanaphore, l'antistrophe et la gradation 


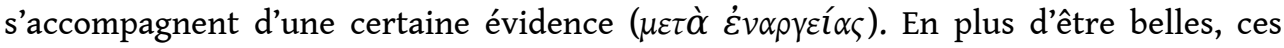
figures sont porteuses d'évidence, parce que, selon l'analyse de Michel Patillon ${ }^{95}$, elles arrêtent l'attention sur le signifiant et en même temps sur le signifié grâce au retour du signifiant en une position remarquable.

Dans l'exemple de gradation qu'il donne, le bel effet caractéristique de l'éclat et de la vivacité due à la brièveté des côlons classe l'énoncé du côté de l'éclat et de la vivacité, car, dit Hermogène, les choses vives sont aussi belles et éclatantes. Cependant, le procédé de gradation lui confère également de l'évidence. Cette figure, qui tire son nom, comme l'a rappelé le rhéteur Alexandros, d'une métaphore qui la compare à une échelle, consiste à répéter en début de vers ou de côlon le mot par lequel s'est achevé le vers ou côlon précédent :

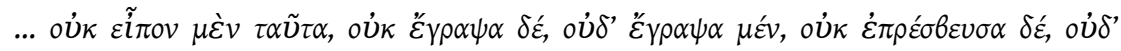

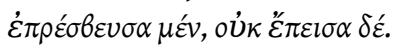

Il n'y a pas eu de ma part discours sans projet de décret, ni projet de décret sans ambassade, ni ambassade sans persuasion ${ }^{96}$.

\section{Apport d'Hermogène au débat sur les figures dites gorgianiques}

L'apport d'Hermogène au débat sur les figures ornementales est important, car sa théorie résulte d'un essai de résolution des problèmes qu'elles soulèvent en rhétorique. Hermogène relève cette gageure en déterminant la nature et le rôle des figures dites gorgianiques comme composants de la beauté dans le discours politique, et en indiquant très précisément comment les utiliser. Il en justifie pleinement l'emploi sans encourir le reproche d'approuver des moyens sophistiques. Il ne s'agit en effet nullement, pour lui, de prôner l'imitation d'Isocrate, représentant des tendances psychagogiques de l'éloquence - Hermogène l'oppose à Démosthène -, mais de tirer d'elles le meilleur parti dans l'économie du discours démosthénien. Paradoxalement, c'est en limitant le rôle des figures gorgianiques à la seule dimension esthétique qu'il y réussit. L'absence, dans les procédés de la beauté hermogénienne, de l'antithèse est en effet remarquable. Celle-ci, étroitement associée à la parisose et à la paromoïose dans la Rhétorique à Alexandre et chez Aristote, en avait été peut-être séparée dans la théorie de Théophraste, du moins d'après le modeste premier fragment que nous avons cité, mais après lui, Denys d'Halicarnasse l'a de nouveau comptée sans aucune hésitation au nombre des gorgianismes. Alors que Théophraste avait séparé l'antithèse, procédé acceptable d'une rhétorique philosophique, de la parisose et de la paromoïose, tours inefficaces à ses yeux d'une rhétorique poétique, Hermogène, rigoureux, distingue à son tour la parisose de l'antithèse, qu'il ne mentionne pas, car c'est l'ornement, purement esthétique, qu'il retient dans cette figure, comme en témoigne la nature de la catégorie de la beauté, constituée seulement de composants relevant de l'expression par opposition au contenu. L'aspect sémantique impliqué par l'antithèse ne peut être pris en compte dans la catégorie de la beauté telle qu'Hermogène la conçoit. Au contraire de Théophraste, il ne réduit pas la parisose à un procédé puéril, et contrairement à Démétrios, il ne déconseille pas l'emploi des antithèses, des parisoses et des paromoïoses. Le système d'opposition des catégories stylistiques contribue à définir la juste place que l'ornement doit tenir dans le discours démosthénien. Destinée à combattre l'âpreté d'un discours qui se contenterait de n'être que clair et grand, la beauté, qui tomberait dans la nonchalance et la platitude si ne s'y joignait quelque vivacité, 
est elle-même ainsi contenue par une catégorie qui la limite et en réduit l'impression sur l'auditeur.

Dans cette perspective, les parisoses hermogéniennes ne doivent pas s'exhiber mais au contraire agir d'une façon atténuée. Hermogène a comme Théophraste et Démétrios reconnu le danger d'une beauté trop voyante. La recherche esthétique s'oppose à la crédibilité du discours, car celle-ci dépend de catégories stylistiques différentes, l'éthos et la sincérité, qui excluent tout jeu formel. C'est ainsi que dans sa théorie, Hermogène s'attache avec insistance à indiquer les moyens d'atténuer le caractère trop manifeste de ces figures. Le discours démosthénien, c'est un point important, recourt à la beauté, non pour contraindre l'auditeur «à manifester son approbation du geste et de la voix ${ }^{97}$ ", mais pour conférer un charme discret à l'ensemble du discours. La beauté sera d'autant plus nécessaire, dans ses composants principaux ${ }^{98}$, que les pensées seront denses et exigeront d'être revêtues par elle de quelque grâce : elle sollicitera l'attention de l'auditeur et l'empêchera de se laisser rebuter par la densité et la compacité des idées ${ }^{99}$. Ces dernières considérations rejoignent celles de Denys d'Halicarnasse dans le Démosthène sur l'emploi des figures gorgianiques dans les sujets rébarbatifs, mais l'analyse hermogénienne est plus fine. Non seulement elle a précisé les modalités réalisant les figures de la beauté atténuées, mais elle indique plusieurs composants de cette beauté quand Denys se borne à la seule mention des figures. De plus, le mélange des catégories stylistiques permet de discerner dans le discours démosthénien des énoncés où se joignent parfaitement beauté et vivacité, et définit au plus près le style démosthénien. Hermogène écrit lui-même, pour marquer la différence qui le sépare de ses prédécesseurs :

découvrir ce qu'il (sc. Démosthène) doit toujours et partout aux mélanges, lui qui, lorsqu'il délibère, n'exclut pas entièrement de son discours le style judiciaire et le style panégyrique [...], peut-être cela ne sera-t-il pas trop difficile pour qui n'en fait pas une étude superficielle. En revanche, découvrir que, pour obtenir cette qualité de discours, il a employé, comme des éléments en quelque sorte, ces espèces stylistiques du discours, dont la combinaison même donne aussi bien le style panégyrique lui-même que tous les autres genres de discours, voilà qui est très difficile, me semble-t-il (Catégories stylistiques, I, 1, 11-12).

\section{Les principes hermogéniens sur le bon usage de la beauté infléchis par la tradition byzantine}

59 Michel Patillon a démontré le rayonnement de la doctrine hermogénienne à Byzance dans ses travaux sur le Corpus rhetoricum ${ }^{100}$, une vaste somme ayant fourni pendant de nombreux siècles le socle de l'enseignement rhétorique dans le monde grec. Au cours

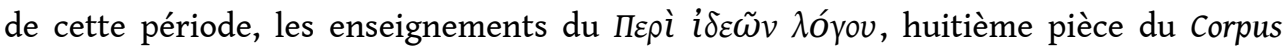
rhetoricum, ont fait l'objet de constantes réélaborations qui témoignent de l'évolution des normes stylistiques byzantines. L'emploi des figures de la beauté s'est notamment amplifié, comme nous le verrons maintenant à propos d'une figure en particulier, la gradation.

Insérée dans l'un des opuscules accompagnant le Corpus rhetoricum proprement dit, un De figuris ${ }^{101}$ dont la matière est empruntée à Hermogène et datable des $\mathrm{V}^{\mathrm{e}}-\mathrm{VI}^{\mathrm{e}}$ siècles ${ }^{102}$, une longue scolie ${ }^{103}$, certainement antérieure au $\mathrm{IX}^{\mathrm{e}}$ siècle ${ }^{104}$, révise en profondeur les recommandations hermogéniennes sur les figures de la beauté. Cette scolie, qu'on lira par étapes dans les pages suivantes ${ }^{105}$, se présente comme un copieux complément à la 
maigre «fiche » sur la gradation ( $\kappa \lambda \uparrow \mu \alpha \kappa \omega \tau o ́ v), 46^{\mathrm{e}}$ figure du De figuris. Un tel ajout a pour finalité de constater la récurrence de la gradation chez des auteurs chrétiens de premier plan et donc d'en consacrer l'usage. Certaines indications font en outre comprendre le rôle explicatif et productif de la quadripartita ratio, qui était au cœur de l'apprentissage des figures, dans l'aménagement de la doctrine hermogénienne. Trois faits remarquables sont : 1) que le scoliaste théorise de son propre chef une forme de gradation atténuée absente de l'œuvre d'Hermogène, 2) qu'il assimile Grégoire de Nazianze à Démosthène, 3) qu'il accorde enfin une haute valeur stylistique à la gradation en privilégiant un aspect qu'Hermogène jugeait secondaire, l'évidence que cette figure confère au discours.

61 Tandis que l'auteur du De figuris s'était borné à fournir le seul exemple hermogénien de

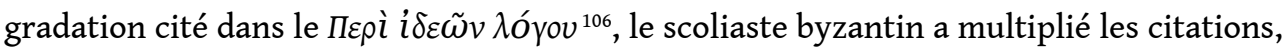
dont certaines sont commentées : un passage de l'Iliade (II, 101-7) sur la transmission du sceptre des Atrides complété d'une citation du premier chant (I, 6-7) ; quatre exemples de Grégoire de Nazianze (Éloge funèbre de saint Basile, Lettre à Clédonios 101, Sur la Fête des Lumières, Sur le saint Baptême); trois citations de Jean Chrysostome (Commentaire sur les Actes des Apôtres, Explications des Psaumes) ; un exemple biblique tiré de la Deuxième Épitre de Pierre. Cette simple énumération dénoncerait à elle seule l'intérêt nouveau du

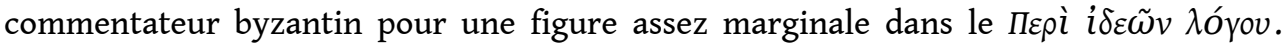
L'ordre de ces exemples, sur lequel nous reviendrons, est loin d'être indifférent mais il sera plus commode d'en rendre raison après une analyse détaillée de chaque exemple.

\section{Analyse des exemples}

\section{a. Iliade, II 101-7 et I 6-7}

Le premier exemple est une gradation d'Homère qualifiée de gracieuse ( $\left.\dot{\omega}_{\rho} \alpha \tilde{\imath} o v\right)$. Le choix de ce terme, conforme à la doctrine d'Hermogène, s'applique au discours énonçant une pensée propre à la catégorie stylistique de la saveur - ici la narration d'événements mythiques -, et recourant aux figures de la beauté et aux épithètes ${ }^{107}$.

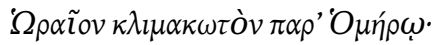

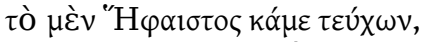

"H

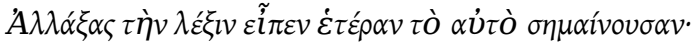

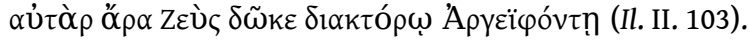

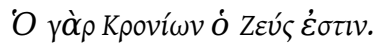

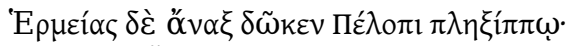

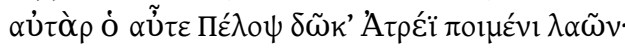

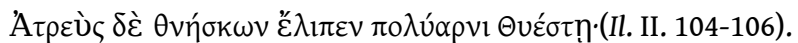

$\tilde{S} \delta \varepsilon \gamma \grave{\alpha} \rho \tau \grave{O} \alpha \tilde{U}<\tau \varepsilon^{108}>\tau \varepsilon \dot{\varepsilon} \theta \varepsilon i k \varepsilon v$.

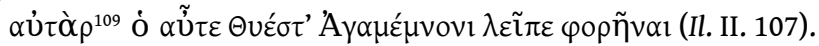

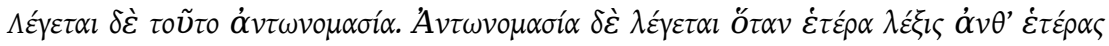

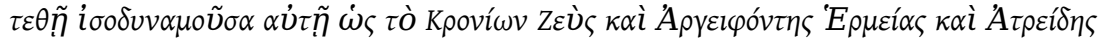

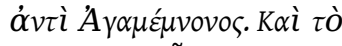

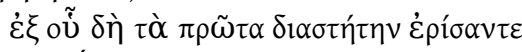

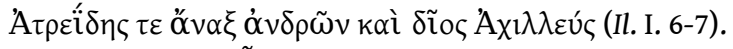

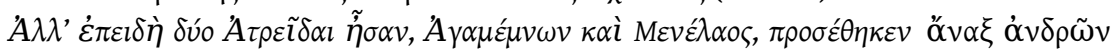

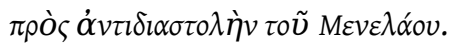

Gradation gracieuse chez Homère : C'est celui [sc. le sceptre des Atrides] qu'Héphaïstos a ouvré, 
Héphaïstos l'a remis à Zeus, Fils de Cronos, souverain. (Il. II. 101-102)

Il a changé le mot et en a employé un autre ayant la même signification : Puis Zeus l'a remis au Messager, Tueur d'Argos. (Il. II. 103)

Le fils de Cronos est Zeus.

Hermès souverain l'a remis à Pélops, piqueur de cavales.

Puis, à son tour, Pélops l'a remis à Atrée, le pasteur d'hommes.

Atrée mourant l'a laissé à l'opulent Thyeste. (Il. II. 104-106)

Ici, il a mis à son tour :

Puis, à son tour, Thyeste aux mains d'Agamemnon l'a laissé (Il. II. 107).

Ce procédé s'appelle antonomase. On emploie le terme d'antonomase lorsqu'un mot

équivalent à un autre mot prend sa place: «Fils de Cronos ", «Zeus »; « le Tueur

d'Argos », « Hermès »; « l'Atride » pour « Agamemnon ». Il y a :

Du jour où, pour commencer, ils se divisèrent à la suite d'une querelle,

L'Atride, souverain des hommes, et le divin Achille (Il. I. 6-7).

Mais puisqu'il existait deux Atrides, Agamemnon et Ménélas, il a ajouté « souverain

des hommes » pour le distinguer de Ménélas.

Les explications visent la plupart à attirer l'attention sur le procédé d'antonomase, un trope consistant à substituer une épithète au nom propre d'une personne ou d'un personnage ou à ajouter, sous la forme d'une apposition, une expression rendant possible l'identification. Homère emploie ici l'antonomase dans une intention esthétique. Les expressions "Fils de Cronos », apposé à $\Delta i \grave{~ a ̀ ~ l a ~ f i n ~ d u ~ v e r s ~ I I . ~ 102, ~ e t ~}$ "Tueur d'Argos », substitué à 'E $\rho \mu \varepsilon i ́ \alpha \varsigma$ à la fin du vers II. 103, préviennent une stricte répétition au début des vers 103 et 104. Les caractéristiques de la gradation sont ainsi respectées, puisque le référent est identique de vers à vers, cependant l'expression gagne en variété et offre même à l'auditeur ou au lecteur le plaisir de reconnaître un personnage indirectement nommé. La mention des antonomases «Atride» et "souverain des hommes » aux vers I. 6-7 sert à différencier dans un but pédagogique l'antonomase à visée esthétique de celle qui sert à clarifier le propos : le syntagme "souverain des hommes» du vers I. 7, analysé par le commentateur comme une antonomase « au second degré » apposée à l'antonomase « Atride », permet d'identifier sans ambiguïté Agamemnon, de la même manière que, par exemple, chez Georges Choeroboscos, les antonomases tirées de caractéristiques accidentelles - bronzier, charpentier - permettent d'identifier une personne parmi celles portant le même nom $^{110}$.

Bien que le scoliaste ne le mentionne pas, un second procédé atténuant la rigidité de la gradation a été observé dans ce passage, expliqué par une scolie exégétique de l'Iliade :

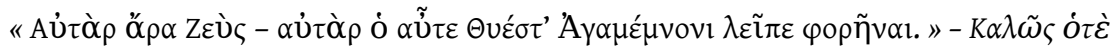

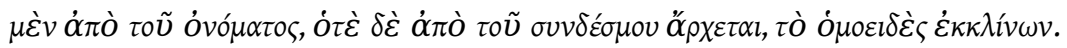

« Puis, Zeus - Puis, à son tour, Thyeste aux mains d'Agamemnon l'a laissé. » - D'une belle manière tantôt il [sc. Homère] commence par le nom, tantôt par la conjonction, évitant l'uniformité ${ }^{111}$

En effet, alors que dans les vers II. 103, 105 et 107, Homère ne respecte pas strictement le schéma de la gradation mais diffère la répétition du nom des souverains par

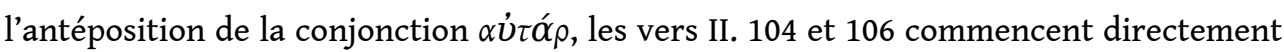
et selon le schéma attendu par le nom du personnage qui reçoit le sceptre. C'est cette alternance qui est perçue comme un raffinement d'expression, d'après un principe cher à Denys voulant que la variété produise de l'agrément :

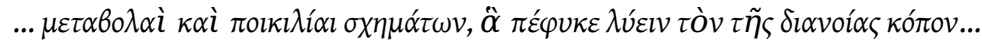

... les changements et les variations de figures, qui rompent naturellement la

lassitude de l'esprit... ${ }^{112}$ 
premier exemple donné par notre scoliaste ajoute donc à la définition hermogénienne des précisions importantes: la gradation admet l'ajout et la substitution dans le but d'assouplir la rigidité de la forme qu'elle réalise.

\section{b. Éloge funèbre de saint Basile}

Le commentateur byzantin établit ensuite un parallèle qui fait de Grégoire de Nazianze l'imitateur de Démosthène. L'exemple choisi est tiré de l'Éloge funèbre de saint Basile,

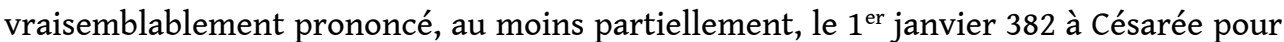
la date anniversaire du décès de Basile, mort en 378. La citation, extraite du $\S 32$, évoque, comme il est d'usage d'après les lieux de l'éloge, les actions du défunt et son dévouement à l'Église orthodoxe dans sa lutte contre l'arianisme.

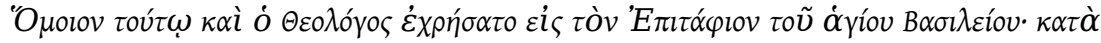

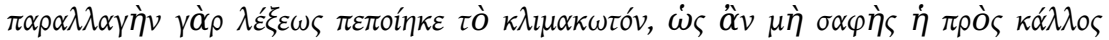

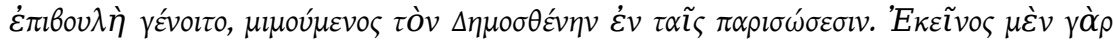

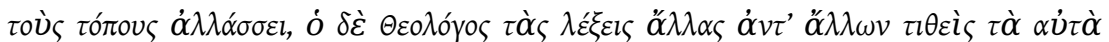

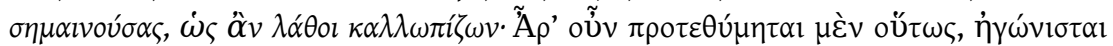

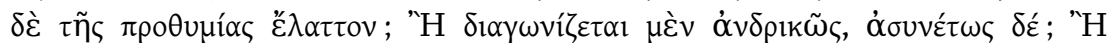

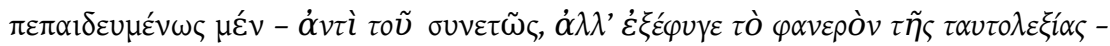

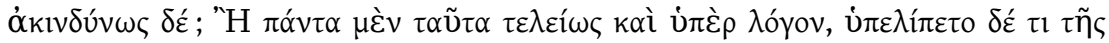

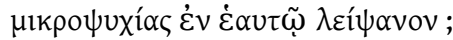

Le Théologien emploie lui aussi un procédé pareil à celui-ci [sc. l'exemple homérique précédent] dans le Discours funèbre de saint Basile. C'est en effet par substitution de mot qu'il réalise la gradation, afin que ne soit pas manifeste l'intention esthétique, à l'imitation de Démosthène dans les parisoses. Celui-ci change en effet les emplacements, tandis que le Théologien change les mots, en en mettant certains pour d'autres, dotés de la même signification, afin d'embellir le discours sans le montrer : S'il fait donc montre de tant d'ardeur, se bat-il au-dessous de cette ardeur? Et s'il combat jusqu'au bout courageusement, est-ce inintelligemment? Et s'il le fait savamment (équivalant à intelligemment, cependant il a évité le caractère voyant de la répétition), est-ce sans que ce soit dangereusement? Et s'il accomplit tout cela parfaitement et mieux qu'on ne saurait dire, est-il resté en lui quelque trace d'abattement ${ }^{113}$ ?

Bien que cet exemple ait été introduit en raison de sa similitude avec l'exemple de gradation homérique, c'est davantage à Démosthène qu'au poète que Grégoire est assimilé. Tout comme l'orateur grec usait de parisoses atténuées par déplacement ( $\tau$ ò̀ $\varsigma$

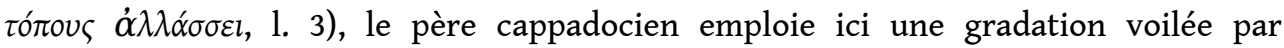

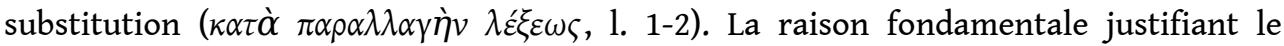
rapprochement entre Grégoire et Démosthène réside dans l'intention plus que dans les moyens, car tous deux ont embelli leur discours sans le montrer. Les mots « $\dot{\omega} \varsigma \hat{\alpha} v \mu \grave{\eta}$

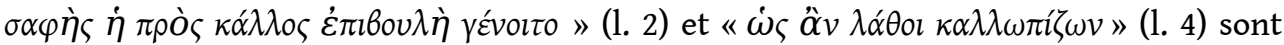
d'ailleurs une quasi citation d'Hermogène à propos d'une parisose atténuée

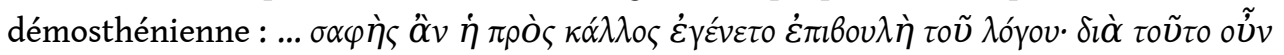

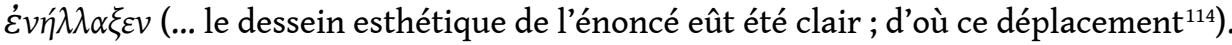

Grégoire, contrairement à ce qui se passait avec les antonomases homériques, use délibérément de synonymes et de mots aux finales identiques : $\eta_{\gamma} \omega v_{v l \sigma \tau \alpha l} / \delta i \alpha \gamma \omega v i \zeta \xi \tau \tau \alpha l$

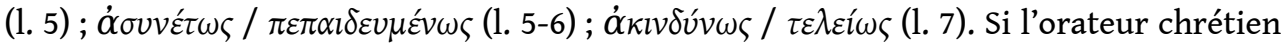

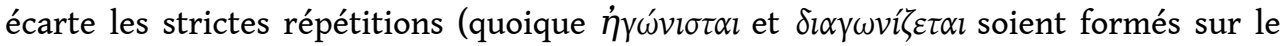
même radical, le préfixe $\delta_{\imath} \alpha$ - et l'opposition temporelle introduisent un écart), il ne renonce pas pour autant à l'effet poétique produit par des finales identiques à une 
place que la récurrence sonore rend prévisible. Remarquons enfin le jeu des particules

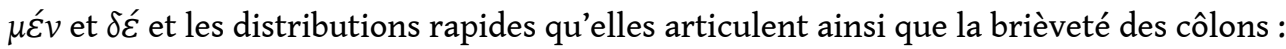
ce sont chez Grégoire les mêmes figures que celles mentionnées par Hermogène lorsqu'il décrit la gradation démosthénienne, alliant beauté, éclat et vivacité, à

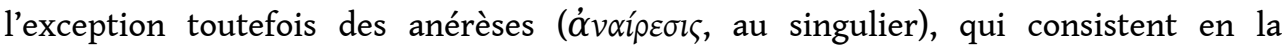
répétition ou épanaphore des négations, auxquelles Grégoire substitue l'interrogation oratoire.

L'exemple choisi correspond donc parfaitement à l'intention critique: adapter la doctrine hermogénienne à des textes postérieurs au II ${ }^{\mathrm{e}}$ siècle, et conférer à Grégoire la même dignité qu'à Démosthène. En s'en tenant à la stricte doctrine des catégories stylistiques, on pourrait s'étonner de l'emploi de figures de la beauté atténuées dans ce passage, car le genre oratoire de l'éloge funèbre n'appartient pas au discours politique mais au discours épidictique (ou panégyrique selon le rhéteur). Or Hermogène les limite au discours politique. Plutôt qu'une preuve de confusion, il faut voir là un signe de la liberté avec laquelle les commentateurs byzantins ont interprété les textes du Corpus rhetoricum. Peut-être le scoliaste rétorquerait-il simplement que l'emploi des figures de la beauté manifestes nuirait à la sincérité du propos et à l'expression du pathos.

Bien que de très nombreuses sources témoignent d'une volonté générale de christianiser l'enseignement rhétorique, notre scolie confirme ici la précocité et la constance des choix critiques byzantins proclamant la supériorité stylistique aussi bien qu'intellectuelle de Grégoire de Nazianze et annonce le jugement de Jean de Sicile, qui ne craint pas de déclarer au $\mathrm{XI}^{\mathrm{e}}$ siècle qu'auprès du Théologue, Démosthène n'était qu'un enfant ${ }^{115}$.

\section{c. Lettre à Clédonios 101}

À partir de l'exemple de la Lettre à Clédonios 101, sept citations illustrent la gradation manifeste. Au-delà d'une volonté évidente de prouver par les faits la validité de normes stylistiques renouvelées - car Hermogène est généralement défavorable à l'emploi de figures de la beauté voyantes dans le discours politique, lequel sert de modèle à la prose -, la variété des exemples prouve la capacité de cette figure à répondre à des besoins différents.

Intégrée partiellement aux Actes du concile d'Éphèse en 431, et reprise intégralement dans les Actes du concile de Chalcédoine en 451, la lettre théologique 101, adressée à Clédonios, a été très tôt considérée comme un discours plutôt qu'une épître. Ce n'est donc pas le style épistolaire qui est en jeu ici, mais un style proche du discours politique, tout au moins démonstratif. Pourtant, Grégoire, loin d'énoncer ici une figure atténuée, martèle les mêmes mots selon le schéma de la gradation :

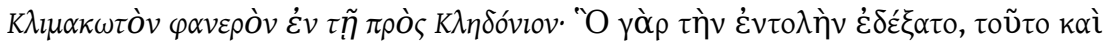

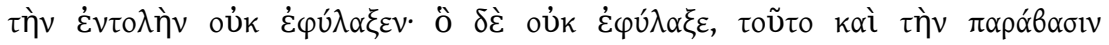

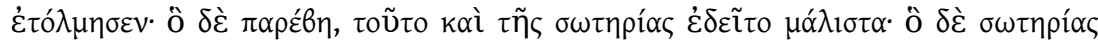

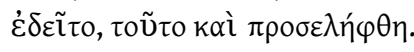

Voici une gradation voyante dans la Lettre à Clédonios : Car il [sc. Adam] en a reçu l'ordre, et pour cela, cet ordre, il ne l'a pas respecté ; il ne l'a pas respecté, et pour cela, il a eu l'audace de l'enfreindre; il l'a enfreint, et pour cela, il a supplié pour son salut; il a supplié pour son salut, et pour cela, il a été secour ${ }^{116}$. 
71 Grégoire évoque ici, à travers Adam, l'âme humaine en tant que cause première du péché originel. Son but est de réfuter les thèses apollinaristes selon lesquelles le Verbe divin ne s'est uni au corps ni à l'âme de l'homme. Or il fallait, dit en substance Grégoire, un remède adapté au mal. Par conséquent, le Verbe devait revêtir, en plus d'un corps, une âme humaine afin d'accomplir sa mission salvatrice. La formulation d'un raisonnement sous forme de gradation n'est pas extrêmement fréquente dans la littérature classique grecque, mais les auteurs chrétiens y recourent souvent. On peut penser que l'écriture biblique a contribué à répandre ce modèle démonstratif. Henry A. Fischel suggère dans un article consacré à la gradation ${ }^{117}$ que les Tannaïm, les sages de la tradition talmudique, et, plus tard, les auteurs des textes néo-testamentaires ont été influencés par les modèles rhétoriques gréco-latins qu'ils se sont appropriés. Il distingue parmi six sortes de gradations, un type particulier qu'il nomme éthique ou éthico-métaphysique, et qui consiste en une chaîne causale de comportements culminant dans une considération d'ordre moral ou métaphysique. C'est à ce type de gradation, qui se retrouve chez quelques auteurs latins et dans la Bible, notamment les textes de Paul et Pierre, que l'on peut assimiler la gradation de la lettre à Clédonios, car la description du comportement d'Adam y exemplifie la vérité à démontrer. Hermogène, qui a vu dans la beauté de la gradation un effet concomitant d'évidence, constatait que Démosthène usait peu de cette figure. Ce n'est pas le cas de Grégoire, chez qui elle est fréquente, avec les autres figures de la beauté manifestes ${ }^{118}$. Répétition et insistance confèrent d'après les critères byzantins autorité et véridicité.

\section{d. Sur la Fête des Lumières et Sur le saint Baptême}

Les deux exemples suivants, tirés des discours Sur la Fête des lumières et Sur le Baptême, confirment la prédilection de Grégoire pour ce que H. A. Fischel nomme gradation éthico-métaphysique :

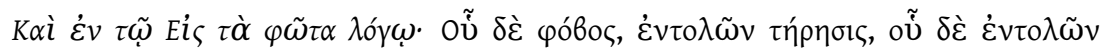

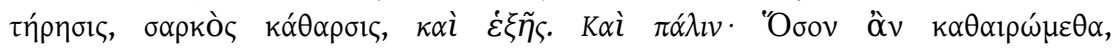

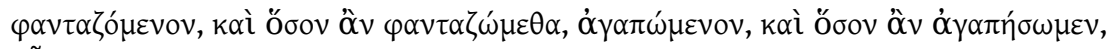

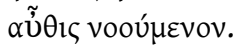

Et dans le Discours sur les Lumières: Où se trouve la peur, se trouve le respect des commandements, où se trouve le respect des commandements, se trouve la purification de la chair ${ }^{119}$, et ainsi de suite. Et encore : plus nous nous purifions, plus elle est imaginée [sc. la lumière divine], plus nous l'imaginons, plus elle est aimée, plus nous l'aimons, plus en retour nous la concevons ${ }^{120}$.

Jean de Sicile a remarqué que certaines gradations étaient fondées sur la nature même $\mathrm{du}$ contenu, tandis que d'autres étaient purement techniques ${ }^{121}$. Son affirmation repose sur le fait que le contenu en question représente les étapes d'une progression spirituelle que la gradation mime. Le point de vue de Jean de Sicile est bien entendu conditionné par ses croyances, mais il est révélateur. Si la gradation est une figure appréciée des auteurs chrétiens, c'est qu'elle exprime au mieux le procès d'une élévation ou d'une chute programmée par une chaîne causale infrangible, comme c'est ici le cas des gradations grégoriennes: la première développe les conséquences bénéfiques de la crainte de Dieu, la seconde l'élévation irréfrénable de l'âme lorsqu'elle rejette le corps et se tourne progressivement vers le divin par l'imagination, puis l'intellect. Ainsi, la gradation devient chez Grégoire une figure privilégiée de l'instruction morale. 
Après les citations de Grégoire, trois autres exemples, empruntés à Jean Chrysostome et au Nouveau Testament, viennent compléter l'exposé du commentateur. Tous ces extraits proviennent probablement d'un ancien commentaire caténaire aux Actes des Apôtres et aux lettres apostoliques ${ }^{122}$.

\section{e. Commentaire caténaire sur les Actes des Apôtres, d'après le Commentaire de l'Épître aux Galates de Jean Chrysostome}

La valeur démonstrative de la gradation est ici utilisée dans le but de défendre Paul de l'accusation d'avoir agi au mépris du principe d'universalité du christianisme. L'apôtre, taisant ses véritables motivations, a fait circoncire son disciple Timothée dans le seul but de ne pas susciter de conflit avec des fidèles judéo-chrétiens, et non par fidélité au judaïsme.

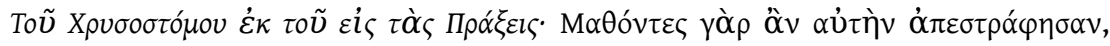

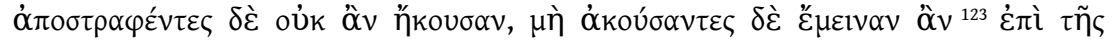

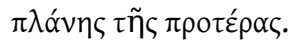

De Chrysostome, tiré du Commentaire des Actes : S'ils l'avaient comprise [sc. la cause de la circoncision de Timothée], ils se seraient détournés, s'ils s'étaient détournés, ils n'auraient pas entendu, s'ils n'avaient pas entendu, ils en seraient restés à leur première erreur ${ }^{124}$.

Cette gradation, qui repose sur une structure hypothétique à l'irréel du passé, expose les conséquences malheureuses qui seraient advenues si Paul n'avait pas caché ses véritables raisons, et prouve a contrario la sagesse de l'apôtre. Il s'agit d'un exemple qui marque encore l'intérêt porté par notre scoliaste à la gradation éthique ou éthicométaphysique.

\section{f. Commentaire caténaire sur les Actes des Apôtres, d'après Jean Chrysostome}

Dans l'exemple suivant, emprunté au Commentaire de l'Épître aux Éphésiens, Chrysostome développe jusqu'à la conséquence extrême - la mort -, les maux engendrés par la division qui s'abat sur une communauté.

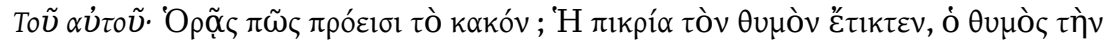

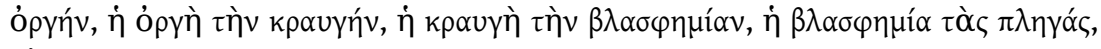

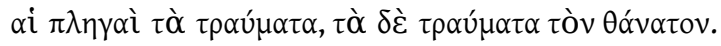

Du même auteur : Vois-tu comment progresse le mal ? L'amertume engendre la passion, la passion la colère, la colère les cris, les cris le blasphème, le blasphème les coups, les coups les blessures, les blessures la mort ${ }^{125}$.

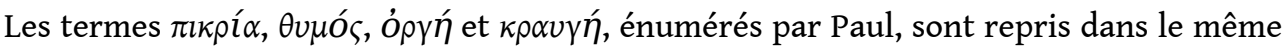
ordre par Jean qui les organise en gradation et les complète par des termes annonçant la violence et la mort. Paul, selon lui, s'est retenu de les nommer. Dans son rapport au texte source, la gradation joue donc ici le rôle d'un instrument herméneutique explicitant une pensée voilée.

\section{g. Explication du Psaume 134 de Jean Chrysostome}

La gradation qui suit, prise de la fin de l'explication du psaume 134, correspond elle aussi au type éthique.

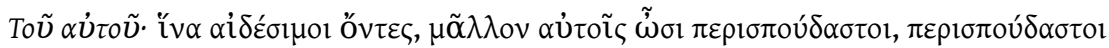

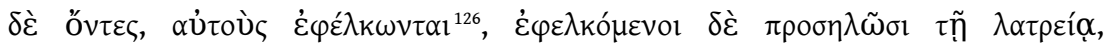

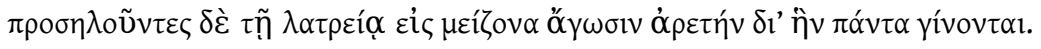


Du même auteur: afin que vénérables [sc. deux lieux sacrés, Sion et Jérusalem], ils soient plus chéris par eux; que chéris, ils les attirent; qu'attirés, ils s'attachent au culte; et qu'attachés au culte, ils fassent grandir en eux la vertu grâce à laquelle tout advient ${ }^{127}$.

Dans l'exégèse qui a fourni cet exemple, Chrysostome explique pourquoi le Psalmiste, pour fortifier la croyance religieuse en l'attachant à des lieux, associe Dieu à Sion, et annonce, à la fin de son exposé, que pour les chrétiens, Jérusalem et Sion seront désormais les étoiles et le ciel. Du point de vue formel, les éléments de cette gradation sont ordonnés selon un ordre croissant marqué par l'emploi des comparatifs $\mu \tilde{\alpha} \lambda \lambda \lambda^{\circ}$ et

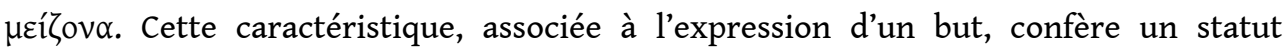
particulier à cette gradation située entre explication et conation.

\section{h. Commentaire caténaire aux Lettres apostoliques, d'après l'apôtre Pierre}

77 La gradation suivante appartient elle aussi au type éthique, mais bien qu'elle obéisse à ce schéma, elle n'a pas la valeur explicative ou démonstrative des citations précédentes car on a plutôt là une figure protreptique uniquement soutenue par la grâce de l'expression.

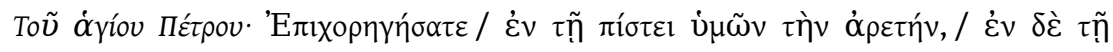

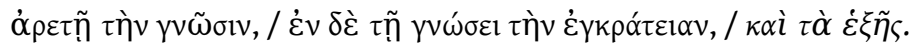

De saint Pierre : Ajoutez à votre foi la vertu, à la vertu la connaissance, à la connaissance la tempérance, et ainsi de suite ${ }^{128}$.

Le scoliaste a en effet illustré ici la beauté produite par une gradation qui persuade plus qu'elle convainc dans cet énoncé de facture poétique où se combinent plusieurs autres procédés : 1) la mise en facteur commun des côlons qui allège la diction ; 2) la cadence régulière des trois derniers côlons presque isosyllabiques $(10 / 9 / 10) ; 3)$ l'épanaphore

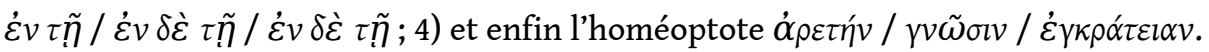

\section{Synthèse}

Placées symétriquement en début et en fin de liste, la Bible païenne qu'est l'Iliade et l'épopée chrétienne qu'est le Nouveau Testament se répondent, justifient de leur autorité les pratiques oratoires des nouveaux auteurs à imiter et marquent le double attachement des lettrés byzantins à la culture hellénique et chrétienne.

Entre ces deux termes, notre scoliaste a méthodiquement ordonné ses exemples en deux groupes. D'après la distinction établie originellement par Hermogène pour le traitement des parisoses, il a forgé à partir de l'observation d'Homère et illustré grâce à l'Éloge funèbre de saint Basile la figure de la gradation atténuée, nettement distincte de la gradation manifeste. Alors que le Rhéteur limitait au discours politique l'emploi des figures atténuées conformément à la pratique de Démosthène, le scoliaste les a transportées dans le discours épidictique.

Les nombreux exemples de gradation manifeste cités ensuite par le commentateur attestent un goût affirmé des grands auteurs grecs chrétiens pour l'expression ornée alliant expressivité et beauté. Certes, la valeur explicative et démonstrative de la gradation éthique repose sur un effet d'évidence qu'avait déjà indiqué Hermogène, produit par la répétition des termes à une place déterminée dans une structure logique, mais ce procédé, rare chez Démosthène et compensé par un certain éclat et de la vivacité, devient plus ample et plus raffiné chez Grégoire de Nazianze et Jean Chrysostome, et suppose chez le lecteur ou l'auditeur byzantin l'existence de normes stylistiques attribuant à la gradation autorité, vérité et beauté. Cette esthétique de la 
parole sacrée caractérisée par le hiératisme formel de la répétition tire son origine des textes bibliques. La gradation manifeste sert ainsi dans de nombreux domaines: la démonstration ou la réfutation; l'instruction morale; l'interprétation; la défense ou l'accusation ; l'exhortation ou la dissuasion ; la séduction ou la persuasion.

\section{L'application de la quadripartita ratio à la doctrine hermogénienne}

Décrire précisément l'usage pédagogique de notre commentaire byzantin demeure une tâche difficile, car il ne constitue qu'une trace d'un enseignement essentiellement délivré à l'oral. Il faut y voir ensemble une fiche de cours, une fiche de révision et le support d'un dialogue pédagogique et d'exercices variés. Tout comme l'exposé de la théorie du texte a exigé un travail d'interprétation fondé sur l'ordre, le nombre, la proportion et le choix des exemples, l'exploration de sa dimension pédagogique ne peut s'appuyer que sur des indices réduits, qui existent cependant. Pour achever cette étude, nous tâcherons d'éclairer cette dimension et en particulier la manière dont la quadripartita ratio a servi à inventer la figure de la gradation atténuée.

\section{a. La quadripartita ratio et la rhétorique}

82 Le schéma antique de la quadripartita ratio postule qu'on peut rendre compte des transformations qui ont lieu dans un ensemble composé d'éléments discrets au moyen de quatre catégories fondamentales: l'addition, la soustraction, la substitution et le déplacement. Son origine est ancienne. Pour Françoise Desbordes ${ }^{129}$, il reprend les catégories de la physique d'Aristote «telles qu'on peut les trouver dans de nombreux textes de la Physique, de la Métaphysique, du Traité du ciel... ». Le philosophe y décrit le mouvement et le changement dont sont affectés les phénomènes physiques en leur appliquant les catégories de la quantité (augmentation, diminution), de la qualité (altération) et du lieu (translation). C'est ainsi que, par exemple, le vin devient vinaigre par altération. F. Desbordes a cependant émis l'hypothèse vraisemblable que «le schéma de la physique aristotélicienne s'inspire lui-même du modèle des manipulations qui sont possibles sur l'écriture » en se fondant sur le Cratyle (394 b). Et de fait, dans le domaine linguistique, la quadripartita ratio a connu la plus grande fortune. Il existe de nombreux exemples d'applications aux différents niveaux et dans les différentes disciplines du domaine linguistique. Les grammairiens l'emploient en phonétique pour décrire les barbarismes et les métaplasmes, en orthographe, en syntaxe pour classer les solécismes ou encore en étymologie et en métrique. Les rhéteurs, quant à eux, l'ont utilisé de diverses manières, dès la Rhétorique à Herennius à propos de la formation des paronomases, et par exemple à propos de l'arrangement des mots chez Denys d'Halicarnasse.

\section{b. La quadripartita ratio et l'enseignement des figures}

Dans le domaine théorique, la quadripartita ratio a concerné - et concerne toujours, si l'on songe aux travaux du groupe $\mu-$, le sujet des figures. Rappelons simplement que Phoebammon ${ }^{130}$ s'en sert pour construire son exposé, que le rhéteur Quintilien l'emploie pour classer les figures grammaticales et pour ordonner son exposé sur les figures de l'expression, et que l'Anonyme de la Vie d'Homère II ${ }^{131} \mathrm{y}$ recourt aussi pour classer les figures homériques. 

un rôle notable dans l'entraînement à l'expression et à l'emploi des figures. Avant notre scoliaste, le rhéteur Aélius Théon, que Michel Patillon situe de préférence au début de la période impériale, ou à la première moitié du $\mathrm{II}^{\mathrm{e}}$ siècle, recourt aussi à la quadripartita ratio dans la paraphrase ${ }^{132}$. Cet exercice d'accompagnement est proposé après la série des Progymnasmata avec quelques autres: lecture, audition, élaboration et contradiction. La pratique de ces exercices est fréquente, sinon quotidienne. Théon ordonne la paraphrase selon la progression suivante :1) transformation de l'expression d'un passage appris selon les quatre opérations de la quadripartita ratio, puis transformation de l'expression selon les modes énonciatif, par exemple assertif, interrogatif ou percontatif ; 2) transformation d'un passage d'auteur dans le but d'en pasticher un autre. Ce second exercice, maitrisé progressivement, s'applique d'abord à des passages appris, puis l'élève est invité à lire et à transposer ce qu'il lit immédiatement. Il s'agit d'abord de textes courts, allongés petit à petit. Comme on peut le voir à ce bref exposé, les opérations de la quadripartita ratio, chez Théon, n'entraînent pas spécifiquement à l'emploi des figures, mais précèdent ce stade.

Plus près de notre commentateur byzantin, un excerptum des Métapoièses de Sopatros, un rhéteur lié au milieu intellectuel athénien $d u I^{e}$ siècle, contient les preuves d'une utilisation de la quadripartita ratio dans l'enseignement des figures. C'est un ouvrage que l'exégète connaissait puisqu'il est cité par l'auteur du De figuris dont le commentateur byzantin complète la notice sur la gradation.

Le terme "métapoièse", qui signifie transformation, désigne un exercice de transposition qui consistait par exemple à passer d'Homère à Démosthène, c'est-à-dire du poétique au politique, en reformulant des passages de l'Iliade en prose. Le résumé des Métapoièses laisse penser que l'ouvrage se donnait une fin surtout pratique :

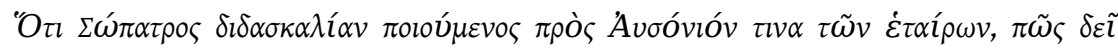

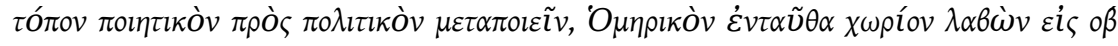

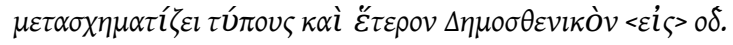

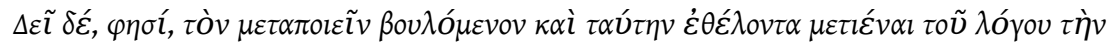

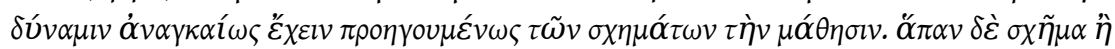

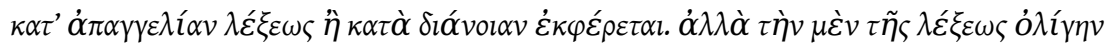

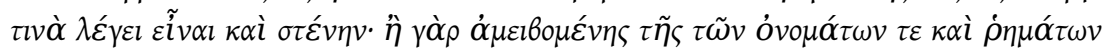

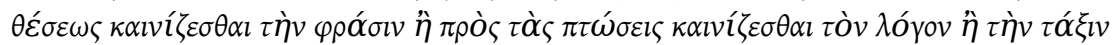

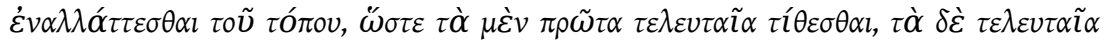

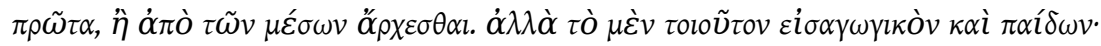

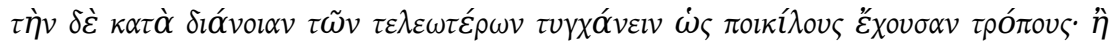

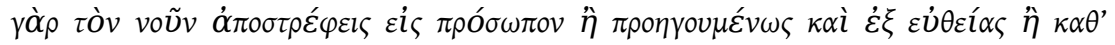

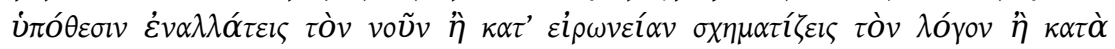
$\beta \alpha \rho \dot{v} \tau \eta \tau \alpha \hat{\eta} \kappa \alpha \tau \alpha \varphi \rho \rho \iota \kappa \tilde{\omega} \varsigma \grave{\eta} \pi \alpha \theta \eta \tau \imath \kappa \tilde{\omega} \varsigma \hat{\eta} \dot{\alpha} v \alpha \kappa \lambda \eta \tau \imath \kappa \tilde{\omega} \varsigma \hat{\eta} \kappa \alpha \tau \dot{\alpha} \pi \alpha \rho \alpha \beta 0 \lambda \dot{\eta} v$.

Sopatros, enseignant à l'un de ses disciples, Ausone, comment on doit transposer un énoncé poétique en énoncé politique, prend un passage d'Homère et en donne quatre-vingt-deux modèles de transpositions, puis d'un autre passage de Démosthène en donne quatre-vingt-quatre.

Il dit que lorsqu'on veut pratiquer la transposition et qu'on désire obtenir cette maîtrise du discours, il est nécessaire de posséder au préalable la connaissance des figures. Toute figure est produite ou bien sur le plan de l'énonciation de l'expression ou bien sur le plan de la pensée. Que, cependant, la transposition de l'expression est pauvre et limitée. Ou bien, en effet, par inversion de la place des noms et des verbes, la diction est modifiée, ou bien le discours est modifié par les désinences, ou bien la disposition du passage est changée, en sorte que le début soit à la fin et la fin au début, ou bien qu'il commence du milieu. Cependant, cela est 
élémentaire et pour les enfants. Mais la transposition sur le plan de la pensée s'adresse aux plus avancés car elle comporte des formulations variées. Ou bien, en effet, l'on apostrophe une personne, ou bien on change le discours en le rendant immédiat et direct, ou bien en introduisant l'hypothèse, ou bien on fait prendre une figure au discours par l'ironie, la sévérité, la cataphore, le pathétique, l'interpellation ou la comparaison ${ }^{133}$.

Sopatros était guidé par les doctrines des catégories stylistiques, notamment Hermogène. Le rédacteur du résumé des Métapoièses précise en effet que ce rhéteur invitait à s'exercer à la transposition en recourant aux figures recensées par d'autres technographes :

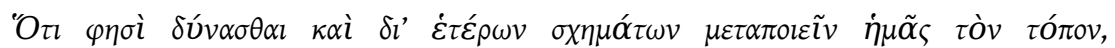

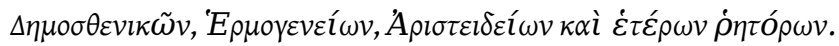

Il dit que nous pouvons aussi transposer le passage au moyen d'autres figures, de Démosthène, d'Hermogène, d'Aristide et d'autres rhéteurs ${ }^{134}$.

On peut identifier les trois ouvrages cités facilement : le premier est celui de Tibérios,

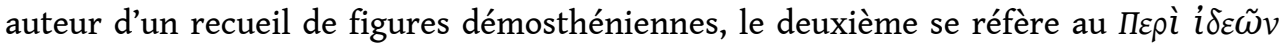
$\lambda o ́$ yov et peut-être au traité Sur l'Invention du Pseudo-Hermogène, le troisième aux Arts rhétoriques du Pseudo-Aristide. D'après ces auteurs, on peut être tenté d'affirmer que la transposition avait pour finalité la maîtrise des catégories stylistiques du discours ${ }^{135}$.

En plus de cet exercice spécifique de l'elocutio, d'autres plus globaux étaient employés par les professeurs de rhétorique afin d'entraîner leurs élèves aux différentes tâches de l'orateur. L'auteur du De figuris complété par le scoliaste avait lui-même composé son répertoire pour un élève en particulier, Ignatios, afin de lui faciliter l'apprentissage des figures ${ }^{136}$. Grâce à son recueil, il était loisible à ce jeune homme de 14 à 16 ans d'apprendre à lire Hermogène, un auteur réputé difficile, de mémoriser les définitions des figures hermogéniennes accompagnées de très nombreux exemples et de s'entraîner à les lire et les réciter. Bien évidemment, les exemples du De figuris, pour la plupart de Démosthène et d'Homère, constituaient aussi un support idéal de transposition.

La transposition, nous dit Sopatros, exige la connaissance des figures. Il s'agissait donc vraisemblablement d'un exercice dont l'apprentissage débutait après le premier cycle d'études chez le grammairien. L'élève avait commencé l'étude de la rhétorique proprement dite et il avait assimilé, en partie du moins, le contenu des manuels de figures classiques. La progression reposait sur la division traditionnelle des figures en deux catégories : figures de l'expression, figures de la pensée. Les traités commencent généralement par un exposé sur les figures de pensée, supérieures en dignité à celles de l'expression, mais Sopatros inverse cet ordre et fait débuter l'apprentissage de la transposition par l'emploi des figures de l'expression dont la manipulation plus aisée convient mieux à une initiation. L'auteur du De figuris dont la scolie sur Grégoire de Nazianze et Jean Chrysostome a été extraite ${ }^{137}$ expose d'ailleurs lui aussi dans cet ordre inhabituel les figures d'expression et les figures de pensée. Deux opérations de la quadripartita ratio sont mentionnées par Sopatros à ce premier niveau, le déplacement

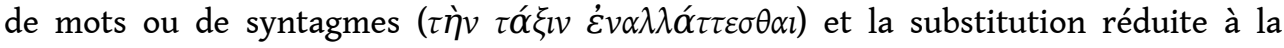

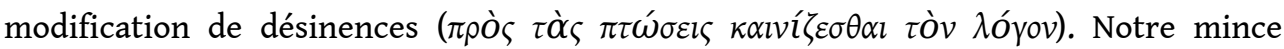
résumé ne désigne pas nommément les opérations complémentaires d'addition et de soustraction, mais on ne peut guère douter de leur emploi précoce. En outre, certaines figures mentionnées par l'excerptum les supposent nécessairement: l'asyndète 
( $\dot{\alpha} \sigma v v \delta \dot{\varepsilon} \tau \omega \varsigma)$, une figure exigeant la soustraction des mots de liaison, l'amplification ( $\dot{\alpha} v \xi \eta \tau \imath \kappa \omega ́ \tau \varepsilon \rho o v)$, fondée sur l'ajout de mots ${ }^{138}$.

90 Comme on peut le constater, le contexte dans lequel s'inscrit notre scolie byzantine sur la gradation atténuée révèle, en plus de l'influence prépondérante d'Hermogène, la continuité de pratiques pédagogiques anciennes fondées sur la quadripartita ratio. Pour notre commentateur, qui était aussi un professeur de rhétorique, les transpositions et d'autres sortes de reformulations mettant en œuvre les opérations d'addition, de soustraction, de déplacement et de substitution étaient bien connues. C'est ce qui explique pourquoi la quadripartita ratio a joué un rôle important lorsqu'il a produit en l'expliquant une nouvelle figure hermogénienne adaptée au corpus qu'il avait à prendre en considération.

\section{c. La quadripartita ratio et la gradation atténuée}

91 Le choix d'Homère n'a rien de surprenant lorsqu'il s'agit d'enseigner les figures, puisqu'une tradition ancienne, reprise dans une biographie byzantine d'Homère, fait de lui leur inventeur :

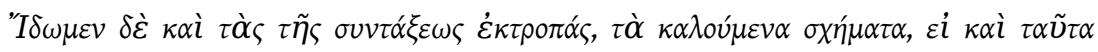

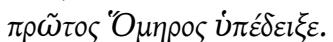

Voyons si Homère a le premier encore montré l'usage des tours de construction qu'on nomme figures ${ }^{139}$.

Après cette question de pure forme, l'auteur de la biographie énumère un grand nombre de figures illustrées d'exemples homériques.

Dans le cas de la gradation, les vers qui narrent la transmission du sceptre des Atrides constituaient l'exemple par excellence. Ce passage est cité dans de nombreux textes techniques, par exemple les traités de figures d'Alexandros, du Pseudo-Hérodien, de Tibérios, ou encore les commentaires à l'Iliade d'Eustathe de Thessalonique. C'est donc à une tradition scolaire pluriséculaire que renvoie le scoliaste lorsqu'il évoque le Poète.

L'originalité de son exégèse, cependant, est de rapprocher les antonomases homériques de l'emploi de synonymes chez Grégoire au moyen de la quadripartita ratio. Dans un premier cas, en effet, Homère effectue une opération d'addition :

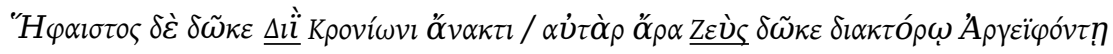

[Il. II. 102-103 : Héphaïstos l'a remis à Zeus, Fils de Cronos, souverain. / Puis Zeus l'a remis au Messager, Tueur d'Argos].

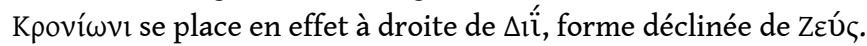

Dans un second cas, il effectue une substitution sans addition :

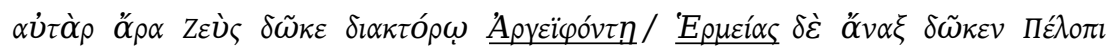
$\pi \lambda \eta \xi i \pi \pi \omega$ (Il. II. 103-104).

Puis Zeus l'a remis au Messager, Tueur d'Argos. / Hermès souverain l'a remis à

Pélops, piqueur de cavales (Il. II. 103-104).

Quant à Grégoire de Nazianze, il réalise en recourant à la synonymie une opération de substitution.

D'Homère à Grégoire, pourtant, la même analyse n'est pas reconduite mécaniquement : bien que des opérations fondamentalement identiques soient identifiées chez le Poète et le Théologien, le second seulement illustre la doctrine d'Hermogène sur l'atténuation des figures de la beauté. Il est remarquable en effet que le scoliaste se garde de justifier les antonomases homériques par un besoin d'atténuation. C'est le signe d'une distinction capitale entre le niveau des opérations de la quadripartita ratio, jouant le rôle 
de moyens, et le niveau des fins qu'on cherche à atteindre grâce à elles, variables d'un texte à l'autre en fonction de la catégorie stylistique mise en œuvre, dans le cas d'Homère, la saveur, dans celui de Grégoire, la beauté atténuée. Grâce à la mise en rapport des opérations de la quadripartita ratio et des catégories stylistiques hermogéniennes, notre scoliaste, inventeur d'une figure "hermogénienne " inédite, s'est en effet montré capable de renouveler la doctrine des $i \delta \varepsilon ́ \alpha l$, c'est-à-dire de la prolonger tout en la modifiant pour l'adapter à la prose des auteurs chrétiens.

Du point de vue de l'enseignement des figures, la division établie par la scolie entre les gradations atténuées et les gradations manifestes laisse facilement deviner quels exercices de formulation et de transposition étaient proposés pour conduire un élève à la maîtrise de cette figure. Toute la gamme des contenus démonstratifs appelant une formulation belle et expressive pouvait être requise pour entraîner à l'emploi de la gradation manifeste, tandis que les contenus centrés sur l'expression de l'éthos et du pathos fournissaient l'occasion de s'exercer à la production de gradations atténuées. La transposition de gradations d'une forme à l'autre, quant à elle, formatrice mais plus centrée sur la technique et privilégiant l'utilisation consciente des opérations de la quadripartita ratio, était susceptible d'offrir, à terme, une aisance stylistique supérieure. Le fait que notre scoliaste rapproche le recours à la synonymie des procédés d'atténuation démosthéniens touchant aux parisoses prouve en outre qu'il applique le schéma de la quadripartita ratio à la doctrine hermogénienne dans son ensemble :

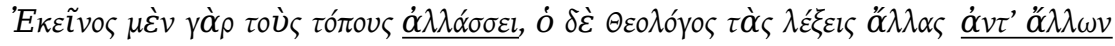
$\tau \imath \theta \varepsilon \grave{c} \varsigma \tau \grave{\alpha} \alpha \dot{v} \tau \grave{\alpha} \sigma \eta \mu \alpha \imath v o v ́ \sigma \alpha \varsigma . .$.

Celui-ci change en effet les emplacements, tandis que le Théologien change les mots, en en mettant certains pour d'autres, dotés de la même signification... ${ }^{140}$

Il était inconcevable en effet que le commentateur ait mentionné isolément la substitution sans une vue d'ensemble qui embrassât tous les procédés d'atténuation. On peut même dire que c'est parce que la doctrine hermogénienne sur les figures atténuées pouvait être interprétée en termes d'addition, de déplacement et de soustraction qu'elle appelait un complément naturel faisant état de la substitution.

Le tableau ci-dessous donne une vue d'ensemble commode des procédés d'atténuation des figures de la beauté hermogéniennes complétés par l'exposé de notre scoliaste.

\begin{tabular}{|l|l|}
\hline Figures de la beauté atténuées & $\begin{array}{l}\text { Opération de la quadripartita ratio sur laquelle repose } \\
\text { l'atténuation }\end{array}$ \\
\hline parisose avec insertion (De id., I, 12,15) & addition \\
\hline $\begin{array}{l}\text { parisose par côlon entier (De id., I, 12, } \\
\text { 19) }\end{array}$ & soustraction \\
\hline $\begin{array}{l}\text { parisose avec déplacement (De id., I, } \\
12,16)\end{array}$ & déplacement \\
\hline $\begin{array}{l}\text { gradation avec substitution (De fig., } \\
\text { p. 134-136) }\end{array}$ & substitution \\
\hline
\end{tabular}


Exception faite du projet rhétorique aristotélicien, au sein duquel les figures dites gorgianiques s'étaient vu assigner une fonction avant tout cognitive, il ressort de notre étude que les rhéteurs et les hommes de lettres ont généralement cantonné ces figures à un rôle esthétique. Cette dimension ornementale est justement ce qui leur a attiré des critiques et leur a valu d'être associées aux approches sophistiques de l'éloquence, dans la mesure où une élocution recherchée ne convient pas à toutes les situations, peut nuire à l'expression de l'éthos et du pathos, en un mot s'oppose à la crédibilité d'un discours offrant les apparences de la sincérité et de la spontanéité.

Confronté à une telle difficulté, Hermogène est le théoricien qui a su le mieux intégrer les figures dites gorgianiques à sa doctrine des $i \delta \varepsilon ́ \alpha l$, les faisant dépendre de la beauté du discours, une catégorie stylistique tempérant celle de la grandeur et tempérée par celle de la vivacité. Hermogène, toutefois, a, malgré cet équilibre, pris soin d'indiquer de manière détaillée plusieurs moyens d'atténuer l'effet esthétique produit par les figures gorgianiques, afin d'en rendre l'emploi plus discret, plus agréable au public... et ainsi plus efficace. En cela encore, ce rhéteur se démarque des autres par la précision de ses enseignements. Il est piquant de constater que ses continuateurs byzantins, pour forger une doctrine apte à décrire et promouvoir la prose de Grégoire de Nazianze et Jean Chrysostome, se sont réclamés d'Hermogène, qui n'aurait pourtant pas approuvé un style chrétien très richement orné alliant aux préoccupations esthétiques un souci d'évidence fondée sur la répétition. L'un de ces exégètes, créant, comme nous l'avons $\mathrm{vu}$, une nouvelle figure "hermogénienne », la gradation atténuée, témoigne par son entreprise qu'il a compris en termes d'ajout, de soustraction, de déplacement et de substitution les procédures liées à la production des figures dites gorgianiques.

De telles opérations, connues sous le nom de quadripartita ratio, simples et fondamentales, antérieures et postérieures à Hermogène, toujours à l'œuvre dans le travail du brouillon, ont pu servir, au-delà des figures de la beauté, à l'enseignement des différentes catégories stylistiques et ont vraisemblablement joué, au cours de l'Antiquité tardive et de la période byzantine, un rôle important dans l'enseignement des figures en général. Tout en constatant leur efficacité, on doit surtout penser à la puissance nouvelle que l'outil conceptuel hermogénien leur a conférée par la mise en évidence des aspects généraux du discours et de leurs composants. C'est en raison d'une pratique scolaire des opérations de la quadripartita ratio que le scoliaste responsable du développement sur Grégoire de Nazianze a perçu, à tort ou à raison, dans le texte hermogénien, le même schéma sous-jacent, mais c'est grâce à la théorie hermogénienne qu'il a pu interpréter les substitutions mises en œuvre par Grégoire comme la marque d'une beauté atténuée due à l'habileté. Le triomphe de Grégoire au $\mathrm{IX}^{\mathrm{e}}$ siècle ${ }^{141}$ doit assurément beaucoup à celui d'Hermogène, antérieur de quelques siècles, dans le monde byzantin. 


\section{NOTES}

1. Souvent appelées "gorgianismes" par les modernes, elles réunissent le plus souvent l'antithèse, la parisose, l'homéotéleute, l'homéoptote et la paronomase, mais d'autres figures peuvent entrer dans la liste selon les auteurs. Je remercie chaleureusement Michel Patillon et Pierre Chiron pour leur aide précieuse, leurs conseils avisés et leur relecture attentive.

2. Hermogène, Les Catégories stylistiques du discours (De ideis), Synopses des exposés sur les ideai, éd. et trad. M. Patillon, Paris, Les Belles Lettres, CUF, 2012.

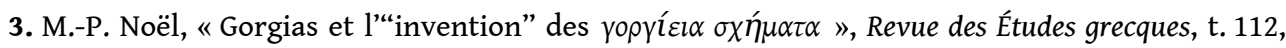
janvier-juin 1999, p. 193-211.

4. La position de Platon est complexe. Il est vrai que le Gorgias caricature et condamne la rhétorique, mais le Phèdre expose le projet d'une rhétorique idéale dont Aristote s'est souvenu.

5. Ps.-Aristote, Rhétorique à Alexandre, texte introduit, éd. et trad. P. Chiron, Paris, Les Belles Lettres, CUF, 2002, ch. 22 (Bekker 23).

6. Ibid., ch. 26-28 (Bekker 27-29). La théorie présentée par ces chapitres est peut-être la partie d'un tout composite réuni postérieurement à la rédaction des parties, mais ce n'est pas la question qui nous occupe ici.

7. Ibid., ch. 26 (Bekker 27).

8. Ibid.

9. Ibid.

10. Ibid., ch. 27 (Bekker 28)

11. Ibid., ch. 26 (Bekker 27).

12. Ibid., ch. 28 (Bekker 29).

13. Ces caractéristiques générales correspondent à trois espèces de similitudes qui ne sont pas citées nommément : la paronomase, l'homéotéleute et l'homéoptote.

14. Rhétorique à Alexandre, op. cit., ch. 28 (Bekker 29).

15. Ces tâches sont au nombre de cinq : invention et disposition des idées et des arguments sous la forme d'un plan ordonné ; énonciation ou mise en mots du contenu ; mémorisation et action oratoire.

16. Aristote, Rhétorique, éd. R. Kassel, Berlin, De Gruyter, 1976, III, ch. 2. Nous traduisons.

17. Ibid., III, 2-4.

18. Ibid., III, 5.

19. Ibid., III, 6 .

20. Ibid., III, 7.

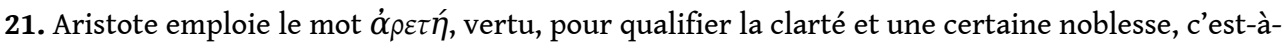
dire le fait que la $\lambda \mathcal{\varepsilon}_{\xi} \zeta_{\zeta}$ ne soit ni trop plate ni trop élevée. Nous employons l'expression latine conventionnelle virtutes dicendi par référence à la forme la plus générale et abstraite de cette théorie stylistique, considérée indépendamment des auteurs et des époques.

22. Ibid., III, 9.

23. Isocrate, Sur l'Échange, 47, éd. et trad. G. Mathieu et É. Brémond, Paris, Les Belles Lettres, CUF, 1942.

24. Isocrate, Contre les Sophistes, 16, éd. et trad. G. Mathieu et É. Brémond, Paris, Les Belles Lettres, CUF, 1929.

25. Isocrate, Panathénaïque, 2, éd. et trad. G. Mathieu et É. Brémond, Paris, Les Belles Lettres, CUF, 1962.

26. Voir P. Chiron, «La Période chez Aristote", dans Théories de la phrase et de la proposition de Platon à Averroès, éd. Ph. Büttgen, S. Diebler et M. Rashed, Paris, Éditions de la rue d'Ulm, 1999, p. 103-130. 
27. Aristote, Rhétorique, op. cit., III, 1.

28. Cicéron, Orator, éd. P. Reis, Leipzig, Teubner, 1963, ch. 79. Voir W. W. Fortenbaugh éd., Theophrastus of Eresus : on his Life and Works, Rutgers University Studies in Classical Humanities, 2, 1985, fr. 684.

29. Denys d'Halicarnasse, De Isocrate, dans Dionysii Halicarnasei quae exstant 5, H. Usener, L. Radermacher, Leipzig, Teubner, 1899, ch. 3 (ou, dans Opuscules rhétoriques, éd. et trad. G. Aujac, Paris, Les Belles Lettres, CUF : t. I, 1978, 3.1, p. 118). Nous traduisons, ici et ensuite. Voir W. W. Fortenbaugh éd., Theophrastus of Eresus: on his Life and Works, New Brunswick, N.J./Oxford, Transaction books, coll. « Rutgers University Studies in Classical Humanities ", 1985, fr. 691. Sur ce fragment, on consultera également W. W. Fortenbaugh, Theophrastus of Eresus, Sources for his life, writtings, thought and influence, Commentary volume 8, Leiden-Boston, Brill, 2005, p. 292-295.

30. Voir G. Kennedy, The Art of Persuasion in Grece, Princeton, Princeton University Press, 1963, p. 276 sq.

31. Voir M.-P. Noël, op. cit.

32. Denys d'Halicarnasse, De Lysia, op. cit., ch. 14 ; dans l'éd. CUF des Opuscules rhétoriques, Paris, Belles Lettres, t. I, 1978, 14.3-4, p. 89 - nous modifions la trad. G. Aujac, ou plus exactement sa reprise dans la trad. P. Chiron, dans P. Chiron, Un rhéteur méconnu : Démétrios (Ps.-Démétrios de Phalère), Essai sur les mutations de la théorie du style à l'époque hellénistique, Paris, Vrin, 2001, p. 100. Voir W. W. Fortenbaugh, Theophrastus of Eresus, Sources for his Life..., op. cit., p. 692.

33. R. Caruso, "Théorie et enseignement de l'antithèse rhétorique en Grèce depuis l'époque classique jusqu'aux débuts de la période byzantine ", Revue de Philologie, de littérature et d'histoire anciennes, 90-1, 2016, p. 7-67.

34. Aristote, Rhétorique, op. cit., II, 2.

35. Denys d'Halicarnasse, De Lysia, op. cit.

36. Ammonius in Aristotelis de interpretatione commentarius, éd. A. Busse, Berlin, Reimer, 1897, p. 65.

37. Ibid.

38. Denys d'Halicarnasse, De Lysia, op. cit., nous traduisons ; l'éditeur (H. Usener) sépare les deux derniers exemples, mais il paraît plausible de les réunir. - Dans l'éd. CUF des Opuscules rhétoriques, t. I, op. cit., 14.4, p. 89.

39. Aristote, Rhétorique, op. cit., III, 7.

40. Ibid., III, 9.

41. Denys d'Halicarnasse, De Lysia, éd. citée, n. 25 ; dans l'éd. CUF des Opuscules rhétoriques, t. I, op. cit., 14.5 , p. 89, 1. 19.

42. Démétrios, Du Style, éd. et trad. P. Chiron, Paris, Les Belles Lettres, CUF, 1993. L'éditeur situe Démétrios au $\mathrm{II}^{\mathrm{e}}$ ou au $\mathrm{I}^{\mathrm{er}}$ siècle avant notre ère.

43. Cornifici Rhetorica ad C. Herennium, éd. G. Calboli, Bologne, Casa Editrice Pàtron, 1969.

44. Démétrios, Du Style, op. cit., introdution, p. LXVI.

45. R. Caruso, «Théorie et enseignement de l'antithèse... », op. cit., p. 35-37.

46. Démétrios, Du Style, op. cit., ch. 27.

47. Ibid., ch. 28.

48. Ibid., ch. 29.

49. Le registre héroï-comique repose également sur un décalage perçu entre un contenu, bas, et une expression élevée.

50. Démétrios, Du Style, op. cit., ch. 29.

51. Ibid., ch. 37.

52. Rhétorique à Herennius, op. cit., IV, XXIII, 32. Nous traduisons.

53. Denys d'Halicarnasse, De antiquis oratoribus, dans Dionysii Halicarnasei quae exstant, op.cit., ch. 1-4.

54. Ibid.

55. Denys d'Halicarnasse, De Demosthenis dictione, dans ibid., ch. 8. 
56. Denys d'Halicarnasse, De antiquis oratoribus, dans ibid., prologue, ch. 3; dans Opuscules rhétoriques, CUF, t. I, op. cit., p. 72.

57. Denys d'Halicarnasse, De Thucydide, dans ibid., ch.22. Nous traduisons; dans Opuscules rhétoriques, CUF, Paris, Belles Lettres, t. IV, 1991, 22.1-2, p. 72.

58. La dette à l'égard de Théophraste est ici patente. On reconnaît les éléments qui, chez le philosophe, constituent l'ornement. Mais chez Denys, ces éléments deviennent, au moins théoriquement, les composants de tout style, et non les composants d'une qualité stylistique.

59. Denys d'Halicarnasse, De Demosthenis dictione, dans Dionysii Halicarnasei quae exstant, op. cit., ch. $1-5$. Nous traduisons.

60. Ibid.

61. L'exposé des genera compositionis (ibid., ch. 35 à la fin) est postérieur à la première partie du Démosthène et à la Composition stylistique (voir M. Patillon, «Introduction », dans Pseudo-Aristide, Arts rhétoriques I, éd. M. Patillon, Paris, Les Belles Lettres, 2002, p. LXI-LXII). Malgré l'unité globale de la théorie de la première à la seconde partie du Démosthène, la place d'Isocrate a évolué : représentant du style intermédiaire dans la première partie, Isocrate devient le représentant en prose de la composition ciselée dans la seconde partie.

62. Voir M.-P. Noël, op. cit. L'expression « dans les gorgianismes » est dans le Démosthène $(5,6)$, passage que Denys cite dans sa «Lettre à Pompée Géminos» (dans Opuscules rhétoriques, CUF, Paris, Belles Lettres, t. V, 1992, p. 84).

63. Denys d'Halicarnasse, De Demosthenis dictione, op. cit., 40. Nous traduisons.

64. Denys d'Halicarnasse, De Isocrate, ibid., 13. Nous traduisons; dans Opuscules rhétoriques, CUF, t. I, op. cit., 13.6, p. 131.

65. Démétrios, Du Style, éd. citée, n. 37, ch. 250.

66. Cicéron, Brutus, éd. H. Malcovati, 1970, Leipzig, Teubner, 1970, ch. 95.

67. Denys d'Halicarnasse, De Lysia, dans Dionysii Halicarnasei quae exstant, op.cit., ch. 3 ; dans Opuscules rhétoriques, CUF, t. I, op. cit., 3.3, p. 77.

68. Denys d'Halicarnasse, De Demosthenis dictione, ibid., ch. 26. Nous traduisons.

69. Ibid., ch. 43. Traduction d'après G. Aujac.

70. Ibid., ch. 44.

71. Ibid., ch. 45.

72. Voir M. Patillon, La Théorie du discours chez Hermogène le rhéteur, Essai sur les structures linguistiques de la rhétorique ancienne, Paris, Les Belles Lettres, Études anciennes, 1988, réimpr. 2010.

73. Voir M. Patillon, dans Pseudo-Aristide, Arts rhétoriques I, op. cit., p. 1-100.

74. Le terme de composant, employé par M. Patillon, se déduit du grec. Hermogène utilise, conformément à l'usage de cette langue, une expression au neutre pluriel, $\dot{\varepsilon} \xi \tilde{\omega} v \ddot{\alpha} \pi \alpha \varsigma \lambda o ́ \gamma o \varsigma$

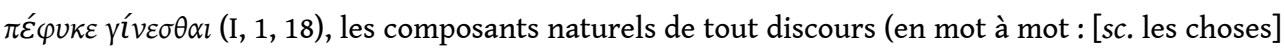
à partir desquelles tout énoncé advient par nature) : la préposition $\dot{\varepsilon} \kappa$ indique la matière,

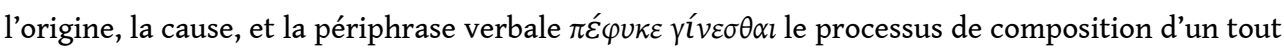
unique. Ces composants, donnés un peu plus loin, sont dits naturels car, présents dans tout énoncé que leur réunion produit, ils s'isolent par l'analyse et peuvent s'utiliser grâce à un art raisonné.

75. Hermogène, Catégories stylistiques, op. cit., I, 1.

76. Hermogène compare les catégories stylistiques à des éléments qu'il est possible de mélanger et de combiner : « $\kappa \alpha \theta \alpha \pi \varepsilon \rho \varepsilon \grave{~} \sigma \tau o \imath x \varepsilon i ́ o l \varsigma \tau \imath \sigma i ̀ ~ \chi \rho \eta \sigma \alpha ́ \mu \varepsilon v o \varsigma ~ » ~(I, 1,12)$, « il [sc. Démosthène] les [sc. les catégories stylistiques] a en quelque sorte employées comme des éléments ».

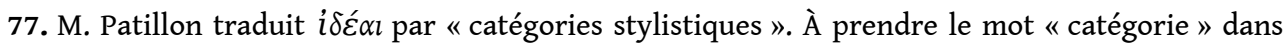
son sens aristotélicien, ce choix met l'accent sur le fait que le nom de chaque catégorie (clarté, grandeur, etc.) provient à l'origine d'une qualité qui se prédique du discours sans que celle-ci en détermine l'essence. Le mot « catégorie » établit ainsi un lien entre la théorie des virtutes dicendi 


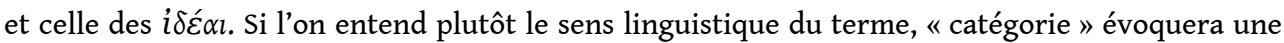
classe dans laquelle seront rangés divers éléments, les composants, selon des critères stylistiques communs. Bien que ce second sens soit tout à fait compatible avec le précédent, il met l'accent sur l'activité critique d'Hermogène, notamment les analyses sémantiques, linguistiques, etc., qui ont abouti au classement des composants dans chaque catégorie. La traduction du grec i $i \varepsilon_{\alpha l}$ par « catégorie stylistique » conserve donc à l'équivalent français une profondeur et une polysémie

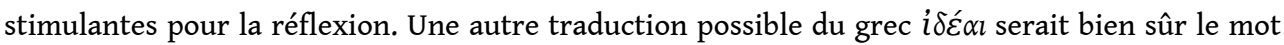

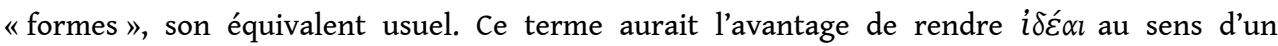
ensemble de qualités immanentes au langage, indépendantes de l'activité critique les portant à notre connaissance ; il naturaliserait en quelque sorte l'analyse hermogénienne, si l'on peut oser un tel terme à propos de langage, et soulignerait sa valeur linguistique aussi bien que rhétorique et stylistique. En tant que formes du langage, les catégories hermogéniennes pourraient ainsi apparaître comme l'aboutissement des recherches menées à travers les siècles par les rhéteurs grecs sur les formes non apophantiques du langage. Si, dans le De interpretatione (17 a2), Aristote assigne à la philosophie l'étude de l'énoncé apophantique, c'est-à-dire déclaratif, susceptible d'être vrai ou faux, il abandonne à d'autres disciplines, rhétorique et poétique, l'examen de formes non apophantiques telles que la prière, ni vraie ni fausse. Protagoras, qui aurait été l'initiateur de telles réflexions, distinguait quatre modalités énonciatives: la question et la réponse, l'ordre et la prière. Les stoïciens ont à leur tour établi une liste plus longue (voir Diogène Laërce, VII, 66) qui a nourri les travaux des grammairiens et des rhéteurs. Ces derniers ont particulièrement étoffé et diversifié les listes des modalités énonciatives pour permettre à l'orateur de mieux influencer son auditoire par l'expression de ses sentiments et d'agir sur lui (par le conseil, la menace, etc.). À cet égard, les $i \delta \varepsilon ́ \alpha l$ hermogéniennes représentent un répertoire complet et ordonné des possibilités du langage. Syrianus, un commentateur d'Hermogène, a bien

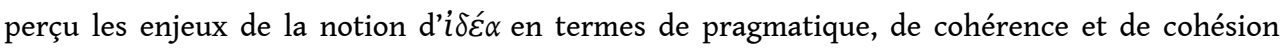
linguistiques, de sémantique et de syntaxe dans la définition générale qu'il en donne (Syriani in Hermogenem commentaria I, éd. H. Rabe, Leipzig, Teubner, 1892, p. 2, 1. 16-19, nous traduisons) :

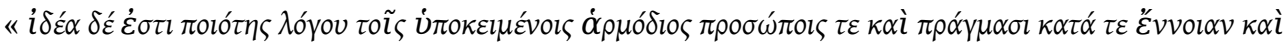

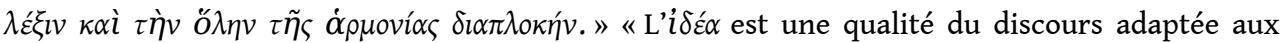
personnes et aux choses tant par la pensée que l'expression et tout le tissu de l'assemblage des mots. »

78. Hermogène, Catégories stylistiques, op. cit., I, 1 à II-9.

79. Dans la poésie, cependant, les trois derniers composants, dont les deux premiers constituent le dernier, n'occupent pas le dernier rang.

80. M. Patillon, «Introduction », dans Hermogène, Catégories stylistiques, op. cit., p. LXIII.

81. M. Patillon, La théorie du discours, op. cit., p. 240 : «Il serait malvenu, pour prendre l'exemple des mots nobles, que les exordes successifs d'une harangue doivent la noblesse de leur expression, l'un uniquement au volume phonétique des mots à voyelles longues ou à diphtongues, un autre uniquement au volume sémantique des mots métaphoriques, un autre uniquement à l'emploi de noms et d'expressions nominales. Une heureuse combinaison demande un emploi plus judicieux de ces classes de mots nobles : l'emploi pour tous les exordes, soit d'une seule classe de façon privilégiée, soit d'un mélange homogène de plusieurs classes. »

82. Il ne s'agit pas de la catégorie stylistique du même nom.

83. M. Patillon, La théorie du discours, op.cit., p. 241.

84. M. Patillon, «Introduction », dans Hermogène, Catégories stylistiques, op. cit., p. LXXXIX.

85. Ibid., I, 12, 13.

86. Ibid., I, 12, 11.

87. Syriani in Hermogenem commentaria I, texte édité par H. Rabe, Leipzig, Teubner, 1892, p. 65.

88. Ch. Walz, Rhetores Graeci, VII ${ }^{2}$, Stuttgart, Tübingen, Londres, Paris, 1834, p. 1037.

89. Ch. Walz, Rhetores Graeci, V, Stuttgart, Tübingen, Londres, Paris, 1833, p. 513. 
90. M. Patillon, La Théorie du discours, op. cit., p. 241.

91. Voir R. Jakobson, Essais de linguistique générale, Paris, Les Éditions de Minuit, 1963, p. 220 sq.

92. Hermogène, Catégories stylistiques, op. cit., I, 12, 15.

93. Ibid., I, 12, 16 .

94. Ibid., I, 12, 19.

95. M. Patillon, La Théorie du discours, op. cit., p. 187.

96. Hermogène, Catégories stylistiques, op. cit., I, 12, 31.

97. Isocrate, Panathénaïque, op. cit. (supra note 25).

98. C'est-à-dire les figures, les assemblages, les pauses et les rythmes.

99. Hermogène, Catégories stylistiques, op. cit., II, 10.

100. Voir M Patillon, "Introduction", dans Corpus rhetoricum I, Anonyme, Préambule à la Rhétorique, Aphthonios, Progymnasmata, Pseudo-Hermogène, Progymnasmata, éd. M. Patillon, Paris, Les Belles Lettres, CUF, 2008, p. V-XI.

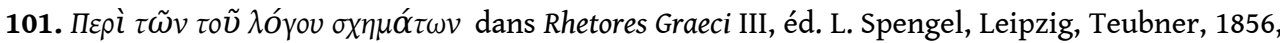
p. $110-160$.

102. R. Caruso, "Datation d'un recueil de figures hermogéniennes", Revue de Philologie, de littérature et d'histoire anciennes, 87-2 (2013), p. 59-87.

103. De figuris, dans Rhetores Graeci III, op. cit., p. 110-160.

104. Le terminus ante quem est très probable, sinon indubitable. Cette question a son importance pour l'histoire des idées, dans la mesure où une datation avant le $x^{e}$ siècle contribuerait à montrer que les érudits du premier humanisme byzantin, s'inspirant d'Hermogène, ont très tôt fait de deux auteurs chrétiens, Grégoire de Nazianze et Jean Chrysostome, les héritiers de Démosthène et Isocrate. Notre scolie apparaît dans deux témoins, le Par. gr. 1983, des $\mathrm{x}^{\mathrm{e}}-\mathrm{XI}^{\mathrm{e}}$ siècles, et le Par. gr. 2977, du XI siècle ; cependant on peut s'appuyer sur une citation qu'elle contient pour la dater d'avant le $\mathrm{Ix}^{\mathrm{e}}$ siècle. L'auteur de la scolie cite en effet un exemple de Jean Chrysostome (voir infra note 124) tiré d'un commentaire caténaire aux Actes des Apôtres, connu sous le nom de Chaîne d'André, mais les témoins les plus anciens de la tradition directe de ce commentaire, l'Oxon. N. C. 58, et le Par. gr. Coislin. 25, respectivement des $\mathrm{XII}^{\mathrm{e}}$ et $\mathrm{x}^{\mathrm{e}}$ siècles,

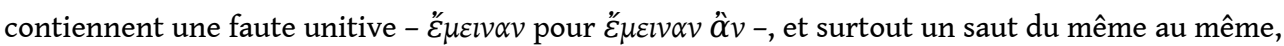
dont notre scolie est exempte. Voici entre crochets les mots omis dans la tradition directe:

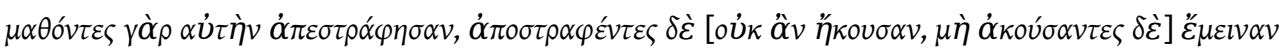
$\hat{\alpha} v$, etc. Étant donné que l'Oxon. N. C. 58 et le Par. gr. Coislin. 25 ne dépendent pas l'un de l'autre, cela signifie que le texte de la scolie est recopié d'un modèle antérieur à celui de ces deux témoins directs ou d'un modèle dérivé de cet exemplaire ancien dont on n'aurait conservé aucune trace... Étant donné l'unilinéarité des traditions manuscrites anciennes, surtout s'agissant d'un recueil composite comme l'est la Chaîne d'André, la première hypothèse paraît bien plus vraisemblable. On pourra consulter l'édition de J. A. Cramer, Catenae Graecorum Patrum in Novum Testamentum, III, Oxonii, e Typographeo, 1844, p. III-XII et 262.

105. Les traductions seront les nôtres.

106. Voir l'exemple référé supra dans la note 96.

107. Hermogène, Catégories stylistiques, op. cit., II, 5, 17.

108. Je conjecture une haplographie de $-\tau \varepsilon \tau \varepsilon^{-}$- réduit à $\tau \varepsilon^{-}$.

109. La leçon $\alpha \dot{U} \tau \grave{\alpha} \rho$ est donnée par le Par. gr. 2977 contre $\alpha \dot{v} \tau \grave{i} \tau o \tilde{v}$ dans le Par. gr. 1983, dont dépendent les autres copies du texte.

110. G. Choeroboscos, De tropis poeticis, dans Rhetores Graeci III, op. cit., p. 250, 1. 3-12.

111. Scholia Graeca in Homeri Iliadem, éd. et trad. H. Erbse, Berlin, De Gruyter, 1969-1988, Il., II, v. 103-7.

112. Denys d'Halicarnasse, De Demosthenis dictione, op. cit., ch. 20. Nous traduisons. 
113. Nous traduisons. Voir Grégoire de Nazianze, Discours funèbres en l'honneur de son frère Césaire et de Basile de Césarée, éd. et trad. F. Boulenger, Paris, Picard, 1908, § 32. Voir notamment p. V-XLII : le point de vue de l'éditeur est daté mais l'introduction contient des informations toujours utiles.

114. Hermogène, Catégories stylistiques, op. cit., I, 12, 16, 7-8.

115. Rhetores Graeci VI, éd. Ch. Walz, Stuttgart, Tübingen, Londres, Paris, 1834, p. 99, 1. 13.

116. Voir Grégoire de Nazianze, éd. J.-P. Migne, Patrologiae cursus completus (series Graeca) (abrégée en MPG), vol. 37, Lettre 101, 52, 1. 1 sq.

117. Voir H. A. Fischel, "The Uses of the sorites (climax, gradatio) in the tannaitic period", Hebrew Union College Annual, 44, 1973, p. 119-151. L'auteur distingue six types principaux de gradations dans les textes bibliques et évangéliques : 1) gradation de transmission, 2) gradation relative à un fait calamiteux ou terrifiant, 3) gradation éthique et éthico-métaphysique, 4) gradation circulaire, 5) gradation défensive, 6) gradation numérique.

118. Voir M. Guignet, Saint Grégoire de Nazianze et la rhétorique, Paris, Alphonse Picard et fils, 1911, p. 90, et plus généralement, p. 82-130.

119. Voir ibid., 1.7 sq.

120. Voir G. de Nazianze, MPG, vol. 36, Hom. 40, 5, p. 364, 1.17 sq.

121. Rhetores Graeci VI, op. cit., p. 340, 1. 14-30.

122. Voir supra note 104. Les deux premiers exemples chrysostomiens et l'exemple biblique figurent bien dans l'édition Cramer de la Chaîne d'André mais présentent, pour les deux premiers, des leçons différentes. Le troisième exemple de Chrysostome, absent de l'édition Cramer, a pu être omis dans les témoins pris en compte ou par l'éditeur.

123. La particule ồ , présente dans le Par. gr. 2977, est absente dans le Par. gr. 1983. Il s'agit d'une haplographie de la séquence $-\alpha v \hat{\alpha} v$ -

124. Voir Jean Chrysostome, MPG, vol. 61, Hom. 2, p. 636, 1. 51 sq.

125. Voir Jean Chrysostome, MPG, vol. 62, Hom. 15, 4, p. 110, 1. 58 sq.

126. Le mot $\mu \tilde{\alpha} \lambda \lambda_{o v}$ avant $\alpha \dot{U} \tau o \grave{\varsigma} \varsigma \dot{\varepsilon} \varphi \dot{\varepsilon} \lambda \kappa \omega \nu \tau \alpha_{l}$ est perdu dans notre texte, mais la tradition directe l'a conservé.

127. Voir Jean Chrysostome, MPG, vol. 55, Explication du psaume 134, 7, p. 399.

128. Voir Septante, Deuxième Épître de Pierre, I, 5.

129. Voir Fr. Desbordes, "Le schéma "addition, soustraction, mutation, métathèse" dans les textes anciens ", Histoire Épistémologie Langage V, 1, 1983, p. 23-30.

130. Phoebammon, De figuris, dans Rhetores Graeci III, op. cit., p. 43-56.

131. [Plutarchus] De Homero, Vita Homeri II, éd. J. F. Kindstrand, Leipzig, Teubner, 1990, p. 20-36.

132. Aelius Théon, Progymnasmata, éd. et trad. M. Patillon, Paris, Les Belles Lettres, CUF, 1997, p. 107-110.

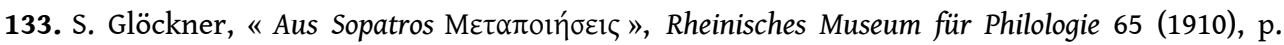
505-514, ici p. 505.

134. Ibid., p. 511.

135. En effet, Tibérios fait de nombreuses allusions à cette doctrine. Quant au Pseudo-Aristide et Hermogène, ce sont, bien entendu, nos principaux représentants de la théorie des catégories stylistiques.

136. Voir R. Caruso, «L'enseignement des figures aux $\mathrm{V}^{\mathrm{e}}-\mathrm{VI}^{\mathrm{e}}$ siècles à travers trois listes hermogéniennes ", Papers on rhetoric XIV (2018), p. 43-58.

137. De figuris, dans Rhetores Graeci III, op. cit., p. 110-160.

138. Rheinisches Museum für Philologie 65, 1910, p. 507 et 508.

139. [Plutarchus] De Homero, op. cit., p. 20.

140. De figuris, dans Rhetores Graeci III, op. cit., p. 134.

141. Voir G. Bady, «Les figures du Théologien : les citations de Grégoire de Nazianze dans les manuels byzantins de figures rhétoriques », Studia Nazianzenica II, Brepols, 2010, p. 257- 322. 


\section{AUTEUR}

RÉGIS CARUSO

Université Paris-Est-Créteil 